\title{
Application of CFD and FEA coupling to predict dynamic behaviour of a flexible barge in regular head waves
}

\author{
P.A.Lakshmynarayanana ${ }^{1}$ and P.Temarel ${ }^{1}$ \\ ${ }^{1}$ Fluid Structure Interactions Group, University of Southampton, U.K
}

\begin{abstract}
The ever increasing size of ships and offshore platforms has resulted in 'softer' hull which require hydroelastic effects to be taken into account when predicting fluid-structure interactions. The majority of such investigations are carried out numerically using potential flow solvers. Although nonlinear potential flow methods are also used, RANS/CFD (Reynolds-averaged Navier-Stokes equations) can fully take into account of nonlinearities. It is important, therefore, to verify and validate the results from such numerical predictions. This paper aims to investigate the symmetric motions and responses of flexible barge in regular waves by coupling RANS/CFD and Finite Element software. The two-way interaction between a fluid solver, Star-CCM+, and a structural solver, Abaqus, is applied by exchanging pressures and nodal displacements more than once every time step, namely implicit coupling scheme. A combination of overset and mesh morphing approaches and finite volume solution to allow for the motions of a body at the free surface is used. The computational results compared with experimental measurements and 2-D linear hydroelastic predictions show good agreement. The discrepancies between the 2-D and CFD/FEA cosimulation arise due to the strong influence of bow and stern radiated waves and the agreement between them improves when the nonlinearities are not as dominant.
\end{abstract}

\section{Introduction}

An accurate prediction of global wave-induced motions and loads is crucial in the design of ships and offshore platforms. In traditional seakeeping analysis, their structural responses are predicted considering them as rigid bodies. Increase in the size of ships and offshore platforms have resulted in more flexible structures which require the flexibility of the structure to be taken into account when calculating motions and responses. In such cases, the deformation of the structure could significantly affect the flow field and the fluid loading, resulting in a fully coupled system. The increased size of ships, particularly in length, has resulted in a lowering of the 2 -node natural frequency of vibration of the hull (Hirdaris \& Temarel 2009). Therefore, hydroelastic effects can have an important influence on the global loads and bending moments of a realistic ship as documented by Hirdaris et al. (2010), Andersen \& Jensen (2014) and Storhaug et al. (2010) on containerships over 8000 TEU. 
Numerical hydroelastic investigations based on potential flow range from linear to partially nonlinear solvers. Bishop \& Price (1979) pioneered this research by developing the theory of (2-D) hydroelasticity of ships which aimed at unifying the linear dynamic analysis of ship symmetric response, using beam theory approximation for the structure and strip theory for the FSI. This theory introduced the concept of generalised modes which accounts for distortional degrees of freedom rather than just predefined rigid body modes. Bishop et al. (1986) introduced the linear 3-D hydroelasticity theory based on frequency domain potential theory. The ship structure is modelled using finite element methods and the fluid actions (radiation) are determined using a pulsating source Green's function. A great deal of progress has been achieved since in the development and application of 3-D hydroelasticity in frequency domain (Wu \& Cui 2009).

Seakeeping problems and ship response evaluation are commonly carried out in frequency domain. They provide faster and accurate solution which can be used in early design stage. Focus on investigating nonlinearities associated with seakeeping problems has encouraged researchers to use time domain solutions. Time domain methods are, thus, becoming more widely used in seakeeping analysis (ITTC. 2011). Kim \& Kim (2009) presented a time domain approach which directly couples BEM and FEM to investigate the hydroelasticity of a flexible floating barge. Good agreement was recorded between the predictions and experimental measurements, but discrepancies were noted at the stern and bow locations, especially when the wave frequency approaches the 2 node wet frequency. Kim et al. (2013) later applied this method to study the springing phenomena of S-175 containership. It was shown that the rigid and flexible body responses of the ship may differ significantly due to the occurrence of distortional natural frequencies. A nonlinear time domain formulation to accurately evaluate whipping loads due to slamming was developed and compared well with experimental results for S-175 container by Wu \& Hermundstad (2002). The total vertical force was divided into a linear and nonlinear modification. They reported satisfactory agreement between model tests and numerical results.

The conventional linear hydroelasticity analyses, using 2D or 3D potential flow within a modal analysis framework and a beam or 3D finite element (FE) structural representation, are constrained as a consequence of the assumptions involved. Incorporation of some nonlinear effects in the aforementioned analyses leads to some improvement in predictions depending, for example, on wave steepness (Park \& Temarel 2007). Nevertheless, the improvements attained are constrained by environmental 
conditions and, naturally, do not allow for viscous effects which are quite important, for example, where roll motion is concerned. Chen et al. (2006) presented a review of existing hydroelasticity theories. The review concluded that development of nonlinear hydroelastic theories in time domain should be the main target to account for the nonlinearities more accurately.

With increasing computational power, fully nonlinear methods are developed using RANS equations. The fluid-structure interactions can be modelled by coupling a fluid solver which solves the nonlinear RANS equations and a structural solver that calculates the distortions using a suitable 2-D or 3-D idealisation of the structure. When coupling fluid and structural solvers one- and two-way coupling approaches can be used. Only the fluid pressures acting on the structure is transferred to the structural solver, for the former; whilst, the structural deformations are also fed back into the fluid solver causing mesh deformations for the two-way coupling. The one-way coupling approach to predict hydroelastic response requires much lesser computational time providing a faster and more economic approach when compared to a two-way coupling. For example, whipping response of a ship in waves revealed reasonable agreement with measurements, however, the wave responses were higher and the local pressure variation at the bow was not captured (Dhavalikar et al. 2015). The lack of structural deformations not fed back to the fluid is causing the differences. More recently, Takami et al. (2018) also simulated the global and local hydroelastic response using a one-way approach and found the results are comparable to the experiments. Nevertheless they noted differences in the whipping frequency components that could be arising due to the omission of added mass effect in the elastic deformations, which may require a two-way coupling.

Oberhagemann et al. (2008) and Oberhagemann et al. (2012) continued the development of the one-way coupling approach by El Moctar et al. (2006) to include two-way elastic coupling. The comparison of one-way and two-way coupling were carried out by studying the hydroelastic effects of slamming induced hull whipping on the sectional loads of large containerships. They found that when the deformations are fed back into the fluid solver, resulting in a two-way coupling, the predicted vertical bending moments, shear forces and accelerations agreed more favourable with the measurements. However, both methods resulted in bending moments that are smaller than the measurements. Paik et al. (2009) also made similar comparisons between the one-way and two-way coupling of S-175 containership with experiments. CFDShip-IOWA and ABAQUS were coupled for 
this investigation to study motions and structural loads during slamming events. They concluded that the one-way coupling approach provided overall a similar quality of solution, i.e. it captured the trends well, to the two-way coupling. However, only the twoway coupling captured the effects of structural deformations in the amplitude and phase of VBM and the oscillations in rigid body accelerations. Seng et al. (2012) evaluated the hydroelastic response of a 9600 TEU containership with forward velocity using a nonlinear strip theory (weakly nonlinear) code Ship star and using coupled CFD/FEA methods. The asymmetry in hogging and sagging measured was of the same ratio only in the CFD calculations and the one-way coupling was unable to predict the higher order harmonic resonance.

Benra et al. (2011) and Paik et al. (2009) discuss the differences between the results obtained using the two methods for two simple flexible models. Their general conclusion, after carefully looking at various cases, was that when dealing with relatively large structural deflections the one-way coupling under predicts the responses by a large amount. The two-way coupling produces results closer to the reality, whereas one-way coupling gives plausible predictions in some cases. One-way coupling might be useful at the initial design stage but to get accurate responses for large vessels when the nonlinearities are overwhelming one would need methods like a two-way coupling.

Various numerical methods have been developed for carrying out accurate numerical predictions of flexible ships; however, the experimental measurements with flexible models are few. Experimental estimations of S175 container ship using flexible models have been extensively validated for various conditions (Watanabe et al. 1989, Wu et al. 2003 and Fonseca \& Guedes Soares 2004). A model test campaign for a 6500 TEU containership was carried out as a JIP to validate the design wave loads obtained from major classes of wave load analysis programs (Hong et al. 2008). Nonlinearities and speed effects investigated in the model tests were reasonably predicted using the numerical codes adopted by classification societies. Malenica et al. (2003) and Remy et al. (2006) conducted experiments on a very flexible barge consisting of twelve rectangular caissons, separated by narrow decks, and connected at the deck level by a uniform flexible steel cross-section. Tests were performed in waves without forward speed and the barge distortions were measured using an optical tracking system at various locations.

In this study a two-way coupling between a finite volume CFD method, namely Star$\mathrm{CCM}+$, and a finite element method, using Abaqus, is applied to compute the 
hydroelastic effects of a flexible barge in regular head waves. This two-way coupling is termed as 'cosimulation' henceforth in this paper. The symmetric distortions computed using the present method are compared with experimental measurements of Remy et al. (2006) and 2-D linear potential flow predictions (Bishop et al. 1977) at a number of wave frequencies. Vertical bending moments (VBM) are also calculated and compared only with the 2-D predictions since measurements were not carried out. The previous publications on this flexible barge using numerical predictions, e.g. Kim et al. (2013), Taghipour et al. (2008), solely focuses on comparing experimental and predicted vertical displacements but no vertical bending moments. This is, therefore, the first paper which attempted to analyse the VBM of this very flexible barge which shows interesting behaviour. 3-D computations are first carried out treating the barge as a rigid body to study the influence of flexibility on the total vertical displacements calculated. The objective is to understand the contribution of nonlinearities on the motions and response of the flexible barge and identify causes of discrepancies in the numerical predictions and their comparison with the measurements.

\section{Numerical Approaches}

\subsection{Finite volume method}

The numerical method employed in Star-CCM+ is a finite volume (FV) method in which the flow is assumed to be governed by RANS equations (Ferziger \& Peric 2003). The RANS equations reduce to the well-known Euler equations for the case of inviscid flow, used in this paper. First, the spatial fluid domain is discretized into a finite number of control volumes (CVs). The integral form of conservation equations (with the initial and boundary conditions) are then applied to cell centres and simplified into an algebraic system of equations solvable by the computer. The governing equations not only contain surface and volume integrals but also time and spatial derivatives. Apart from the conservation equations, the general transport equation for scalar quantities must also be satisfied in the control volume centres. In the numerical simulations of moving coordinates, e.g. when the boundaries are in motion in the flow (see section 2.4), an additional space conservation equation must also be satisfied. The space conservation equation ensures that the continuity and momentum equations are satisfied when the control volumes are moving arbitrarily (Peric et al. 2007). The governing equations are solved using a segregated iterative method, SIMPLE (Semi-Implicit Method for Pressure-Linked Equations) algorithm (Patankar \& Spalding 1972). The Hybrid Gauss- 
Least Square gradient method is used to solve the transport equations. A detailed theoretical background can be found in Ferziger \& Peric (2003)

Free surface flows are implemented using the Volume of Fluid (VOF) tracking method (Hirt \& Nichols 1981). In order to account for the position of free surface in multiphase flows and allow for its arbitrary deformation, an additional transport equation is solved for the volume fraction $c$. The HRIC (High Resolution Interface Capturing) discretization scheme is used for free surface flow along with the VOF tracking in Star$\mathrm{CCM}+(\mathrm{STAR}-\mathrm{CCM}+2012)$ to maintain a sharp interface. The HRIC scheme is carried out by blending of upwind and downwind schemes and further corrected depending on the local Courant number (Muzaferija et al. 1998).

\section{$2.2 \quad$ Finite element method}

Abaqus is a displacement-based method where the basis of the finite element solution is the principle of virtual work or virtual displacements (Dassault Systèmes 2013)

A direct step-by-step integration is adopted in the present study where the governing equations are integrated over discretised time steps $\Delta t$. The temporal integration is performed using a dynamic-implicit scheme which uses the Hilber-Hughes-Taylor implicit operator which is an extension of the Newmark- $\beta$ scheme (Dassault Systèmes 2013 and Clough \& Penzien 1993). In the present method, the barge structure is modelled using 3-D beam elements (B31), which cannot be directly coupled (see section 2.3) with the fluid model in Star-CCM+ since the CFD model can only be coupled with another 3-D surface representing the wetted surface. Hence, membrane elements (SFM3D4) are used to represent the wetted surface area of the ship and are connected to the beam nodes (see section 4.5.2).

\subsection{Cosimulation of CFD and FEM}

To solve the FSI problem with the flexible barge, the fluid and structural solvers run in a coupled manner. The coupling can be broadly classified as (a) One-way and (b) Twoway. When the deformations of the structure can be considered to have a negligible effect on the fluid loading, a one-way coupling is appropriate. In this case the structure is assumed rigid and the calculated pressures are applied as a load history on to the structural model to derive the structural responses. In FSI problems where the deformations are considered as large and can significantly affect the flow field, a two- 
way coupling method is required where the structural deformations, due to the applied fluid pressures, are fed back into the fluid solver to redefine the body and the fluid grid in the overset region, as explained in the next section. A partitioned algorithm is used to execute the two-way coupling where separate solvers for fluid and structure are employed so that information is exchanged at the interface sequentially and solved iteratively. A two-way coupling can be further classified into explicit or implicit coupling. In some FSI problems, e.g. static deformation of a flexible aerofoil in a 'steadystate' airflow, the interaction between the fluid and the structure will approach a steady-state solution where the structural velocities decrease to very small or even zero values. In these cases an explicit coupling, where the exchange of information takes places once per time step, can be used to calculate the 'steady-state' solution (Tallec \& Mouro 2001 and Rugonyi \& Bathe 2001). On the other hand, when the mutual dependency on time is high and a small change in one solver will have an immediate effect on the other an implicit coupling scheme is preferred (Causin et al. 2005). In implicit coupling, used for the flexible barge in this paper, the information is exchanged between the software more than once every time step to simulate the change in hydrodynamic loading and structural velocities. The number of such exchanges per time step is critical for the stability and accuracy of the coupled simulations.

The coupling is done by exchanging pressure and nodal displacements, known as field data, between Star-CCM+ and Abaqus as described in section 4.5. Finite volume codes store the scalar quantities at each cell centre or the face centroid of the mesh and finite element codes store the solution at the vertices of the mesh. In the present coupling method, face-to-face mapping in the coupling uses least square interpolations and nodeto-face mapping uses shape function interpolation. In the shape function interpolation technique, the nodal displacements stored at the vertex of the FE mesh is interpolated to the face centroid of the FE mesh by using the shape functions of the fluid element. In the case of 3-D trimmed Cartesian CFD mesh hexahedral shape function is applied. The CFD and FE meshes need not be conformal for mapping data (STAR-CCM+2012). The fluid pressures at the interface stored at the face centroid of the CVs are mapped on the face centres of the SFM3D4 membrane (surface) elements using least square interpolation. When the nodal displacements are mapped from a finite element mesh to a finite volume mesh a shape function interpolation is used. 


\subsection{Grid adaptation techniques}

In the present investigations grid adaptation, as a consequence of the motion and deformation of the body at the free surface, is implemented using two different methods, namely 'morphing'/deforming mesh and 'overset' grids. The deformation of the body is carried out using 'morphing'. In the case of two-way coupling, the nodal displacements imported from Abaqus are used to redistribute the mesh vertices by generating an interpolation field throughout the fluid domain. Star-CCM+ uses a "space conservation law" to balance the volume of a CV as a function of time and the motion of the surface (Ferziger \& Peric 2003). Morphing could, however, create problems in the case of a body undergoing large motions in waves. The deformation of the entire grid could result in the free surface falling outside the refined region of the grid; additionally, the quality of the cells deformed can become poor resulting in numerical errors. To avoid this problem, an overset grid is used. An area around the body is defined as overset boundary in the overset region (see Figure.2). The overset boundaries are attached to the floating body and move with it freely, with the resultant motion in waves. The motion of the overset grid is relative to the background region that encompasses the fluid domain but is fixed in space. The disadvantage of overset grids is that it is difficult to enforce global conservation, mainly in 3-D problems. For this reason the overset approach should be avoided for flows subject to large solution gradients or large regions of separated flows (Wang 1995 and Tang et al. 2003). Generally, overset grids are highly efficient in the case of free surface flow, where the body undergoes large motions in waves.

In the case of rigid body motion simulations presented in this work, an overset mesh is used to idealise the motion of the body. A combination of overset mesh and mesh morphing is used in the case of the coupled simulations. The nodal displacements from Abaqus, which includes both the rigid body motion and the distortions, cause a deformation of the body by generating an interpolation field as mentioned above. The overset boundaries then move in response to the interpolation field created by the mesh morpher which in turn helps to maintain good quality cells in the region. .

\subsection{2-D Linear Hydroelasticity}

The two-dimensional hydroelasticity method by Bishop et al. (1977) is used as a comparator for the applications. The structure is represented as a Timoshenko beam. The natural frequencies of the barge in vacuo are obtained, in the absence of any 
external actions and structural damping, using a finite difference approach. 2-D strip theory is used to calculate the hydrodynamic actions on the body, using 2-parameter (Lewis) conformal mapping. Frequency dependent added mass and damping coefficients are evaluated. The resultant unified equations of motion in regular waves provide the requisite principal coordinates for a range of wave frequencies. Modal summation is employed to evaluate the vertical displacement and vertical bending moment (VBM) at a specified location along the barge. Rigid body displacements can be evaluated by excluding distortions.

\section{Test Case: Flexible barge}

The experimental model of a flexible barge comprising of 12 connected caissons is considered for validating the present numerical method (Remy et al. 2006). Each caisson is clamped to a steel rod which was placed at $57 \mathrm{~mm}$ above deck level. The rod has a square cross-section of $1 \mathrm{~cm} \times 1 \mathrm{~cm}$ as shown in Figure 1 . All the caissons were rectangular sections except for the bow caisson which has a bevelled shape. The mass of the bow caisson is also slightly different to the other sections. The caissons were separated with a gap of $15 \mathrm{~mm}$ to avoid contact when undergoing distortion in waves. The dimensions of the wave basin are $30 \mathrm{~m} \times 16 \mathrm{~m} \times 1 \mathrm{~m}$. The main characteristics of the barge and the flexible rod are given in Table 1. The model was secured using steel cables and springs to ensure that the natural periods of surge and sway were well above the wave periods. In regular waves, vertical, horizontal and torsional bending was allowed for the model and the vertical distortions of the barge were measured at 6 locations ranging from $0.08 \leq \mathrm{x} / \mathrm{L} \leq 1, \mathrm{x}=0$ denoting AP (Remy et al. 2006).

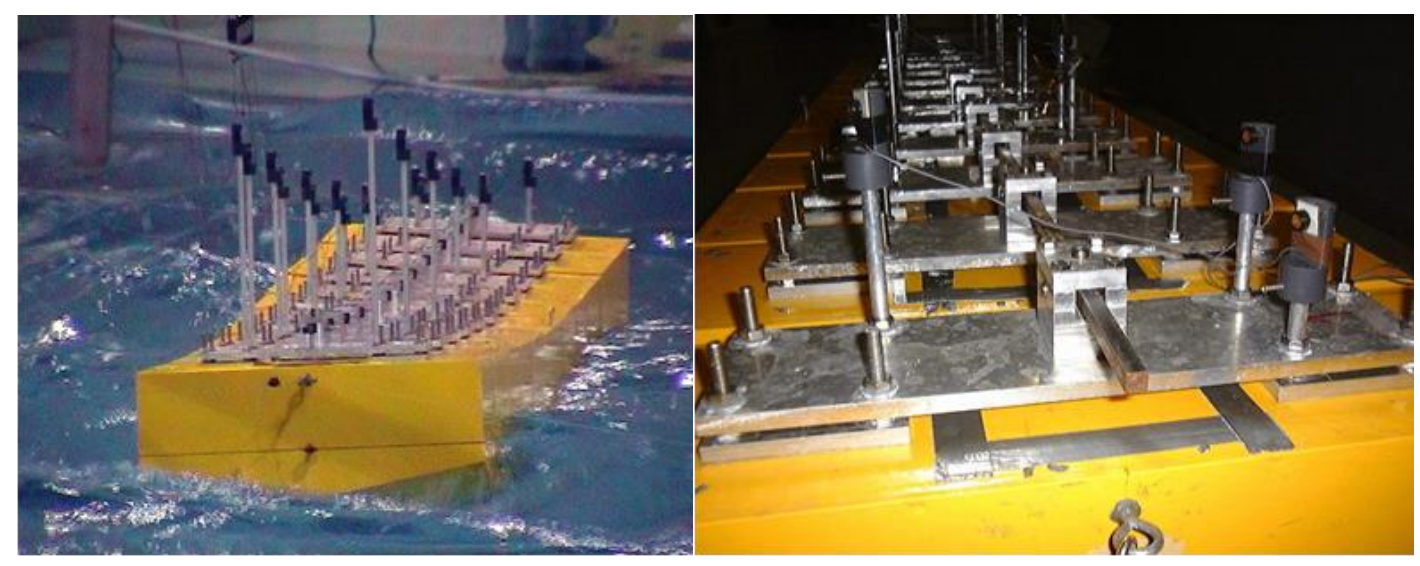

Figure 1: Hydroelastic model of the flexible barge used in the experiments

Table 1: Barge characteristics (Remy et al. 2006) 


$\begin{array}{cc}\text { Length of barge, Lpp (caissons + clearance) } & 2.445 \mathrm{~m} \\ \text { Beam } & 0.6 \mathrm{~m} \\ \text { Depth } & 0.25 \mathrm{~m} \\ \text { Draft } & 0.12 \mathrm{~m} \\ \text { KG } & 0.163 \mathrm{~m} \\ \text { Total mass (caissons + equipment) } & 172.55 \mathrm{~kg} \\ \text { Length of each caisson } & 0.19 \mathrm{~m} \\ \text { Mass of each caisson (except bow) } & 13.7 \mathrm{~kg} \\ \text { Mass of bow caisson } & 10 \mathrm{~kg} \\ \text { Moment of inertia of rod } & 8.33 \times 10^{-10} \mathrm{~m}^{4} \\ \text { (Vertical) Bending stiffness of rod } & 175 \mathrm{~N} \mathrm{~m}{ }^{2} \\ \text { Young's modulus of rod } & 2.1 \times 10^{11} \mathrm{~N} / \mathrm{m}^{2}\end{array}$

\section{Numerical modelling}

\subsection{Barge simulation details}

Two types of simulation were carried out in the present study.

- Response of the barge with no forward velocity in head waves, treated as a rigid body, in head regular waves is calculated for five wave periods shown in Table 2. The objective is to obtain insights on the effect of flexibility on the displacements of the barge in waves. The rigid body displacements calculated using CFD are compared against corresponding 2-D strip theory predictions and experimental measurements

- Response of the barge with no forward velocity, treated as a flexible body, in regular head waves is calculated for the same wave periods by applying the twoway coupling between Star-CCM+ and Abaqus. Total vertical displacements were compared with experimental measurements and 2-D hydroelasticity. However, due to lack of experimental data, 2-D hydroelastic predictions served as the only comparator for the VBM calculated using cosimulation.

Table 2: Test Conditions

\begin{tabular}{lllll}
\hline $\begin{array}{l}\text { Wave Period } \\
(\mathrm{s})\end{array}$ & $\begin{array}{l}\text { Wave Frequency } \\
(\mathrm{rad} / \mathrm{s})\end{array}$ & $\begin{array}{l}\text { Wave Length } \\
(\mathrm{m})\end{array}$ & $\begin{array}{l}\text { Wave } \\
\text { Height }\end{array}$ & $\lambda / \mathrm{L}$ \\
\hline
\end{tabular}




\begin{tabular}{lllll}
\hline 1.8 & 3.490 & 5.058 & $100 \mathrm{~mm}$ & 2.07 \\
1.6 & 3.926 & 3.996 & $100 \mathrm{~mm}$ & 1.63 \\
1.2 & 5.235 & 2.248 & $100 \mathrm{~mm}$ & 0.92 \\
1.0 & 6.283 & 1.561 & $100 \mathrm{~mm}$ & 0.64 \\
0.9 & 6.981 & 1.264 & $50 \mathrm{~mm}$ & 0.52 \\
\hline
\end{tabular}

\subsection{Computational Domain}

The coordinate system of the 3-D domain used in the CFD computations has the $\mathrm{x}$ axis along the barge and $\mathrm{y}$ and $\mathrm{z}$ in the athwartships and vertical directions, respectively. The length of the domain in the inlet-outlet and side wall directions are calculated based on Lpp or wave length $(\lambda)$ from similar ship-wave interaction studies (Seng et al. 2012, Peric et al. 2007 and ITTC 2011). In the present study, the wavelength to barge length $(\lambda / \mathrm{L})$ ratio varies from 2 to 0.5 . For $\lambda / \mathrm{L} \geq 1$, the inlet and wake regions are located at approximately $1.5 \mathrm{X}$ and $2 \mathrm{\lambda}$ from the barge, respectively. The length of both inlet and wake regions for $\lambda / \mathrm{L} \leq 1$ is placed at $3.0 \mathrm{Lpp}$. The total height of the domain is $5.5 \mathrm{~m}$, with $4.0 \mathrm{~m}$ for water depth. In addition to this, a numerical beach of length $2.0 \mathrm{\lambda}$ is provided at the outlet to damp the waves and prevent reflections (Choi \& Yoon 2009). The domain sizes for individual wave frequencies, for both rigid and coupled simulations, are shown in

Table 3. The total distance from the body to outlet is the sum of wake and the damping zone lengths. Symmetry condition is used for rigid body simulations, whereas full domain is modelled for the cosimulation cases.

Table 3: Domain sizes for regular wave periods and lengths (*port side only)

\begin{tabular}{|l|l|l|l|l|l|l|l|}
\hline $\begin{array}{l}\text { Wave } \\
\text { Period } \\
\mathrm{T}_{\mathrm{w}}(\mathrm{s})\end{array}$ & $\begin{array}{l}\text { Wave } \\
\text { Length }\end{array}$ & $\begin{array}{l}\text { Inlet zone } \\
\text { L1 }(\mathrm{m})\end{array}$ & $\begin{array}{l}\text { Wake } \\
\text { Region } \\
\text { L2 }(\mathrm{m})\end{array}$ & $\begin{array}{l}\text { Damping } \\
\text { Zone L3 } \\
(\mathrm{m})\end{array}$ & $\begin{array}{l}\text { Breadth } \\
\text { of } \\
\text { domain } \\
*(\mathrm{~m})\end{array}$ & $\begin{array}{l}\text { Water } \\
\text { Depth } \\
(\mathrm{m})\end{array}$ & $\begin{array}{l}\text { Mesh } \\
\text { Size } \\
(\mathrm{M})\end{array}$ \\
\hline 1.8 & 5.058 & 7.6 & 10 & 10.1 & 8.0 & 4.0 & 2.3 \\
\hline 1.6 & 3.996 & 6.0 & 8.0 & 8.0 & 8.0 & 4.0 & 2.4 \\
\hline 1.2 & 2.248 & 5.0 & 5.0 & 4.5 & 8.0 & 4.0 & 3.15 \\
\hline 1.0 & 1.561 & 6.5 & 6.5 & 3.0 & 8.0 & 4.0 & 6.8 \\
\hline 0.9 & 1.264 & 6.5 & 6.5 & 2.5 & 8.0 & 4.0 & 13.8 \\
\hline
\end{tabular}

\subsection{Meshing Strategy and Boundary Conditions}

A combination of trimmed Cartesian mesh, extruder and overset mesh is used with a grid refinement identical for both rigid and flexible body simulations for identical 
frequencies. Once a core mesh is created using the trimmed Cartesian mesh, the side wall, in y-direction, and the outlet is extruded using user specified extrusion parameters (i.e. number of layers, stretching ratio and extrusion magnitude) to the required distance (as per Table 3). A typical mesh, corresponding to $\mathrm{Tw}=1.8 \mathrm{~s}$ is shown in Figure 2. The instantaneous wave contours for both rigid and flexible motions of the barge for two different frequencies (4.0 rad/s and $7.5 \mathrm{rad} / \mathrm{s}$ ) in Kim \& Kim (2009) showed that the waves radiated around the barge in a circular pattern. Hence, the refinement around the body was also carried out in a manner suitable for the distributed wave pattern, as shown in Figure 2. In the free surface region, 45-60 cells are placed per wavelength and 12-15 cells per wave amplitude (Connel \& Cashman 2016 and Ferrer \& Montlaur 2015). Around 320 cells per wavelength and 160 cells per wavelength are clustered in the near body region (bow, stern and around body) and wave radiation zone, respectively, as shown in Figure.2 (a). The global mesh count for the cosimulation cases varied from 2.3 million to 13.8 million, as illustrated in Table 3. Please note that in the rigid body cases the mesh count was half of that in cosimulation cases. Although the meshing strategy was based on past experience, a limited analysis of mesh density effects was carried out for $\mathrm{Tw}=1 \mathrm{~s}$ and $1.2 \mathrm{~s}$, discussed in section 5.2 .

Boundary conditions for both rigid and flexible bodies were selected so that they mimic the conditions of a towing tank. At the velocity inlet boundary the kinematics of the wave, i.e. the position of the free surface and velocity of the first-order wave are prescribed as field functions. At the outlet boundary, the outlet pressure is set to the hydrostatic pressure of the wave and the position of free surface is specified. The top of the domain is set to velocity inlet as it prevents fluid from sticking to the walls, namely avoiding a velocity gradient happening between the fluid and the wall and in addition directing the flow parallel to the outlet boundary (Tezdogan et al. 2015). For the no-slip wall condition the fluid tangential velocity is set to zero. To save computational effort, a symmetry plane can be used when the geometry, flow field and responses are symmetric. The boundary condition on the symmetry plane ensures that the normal velocity and the normal gradients of all variables are zero i.e., it reflects the flow to the other half of the domain. 


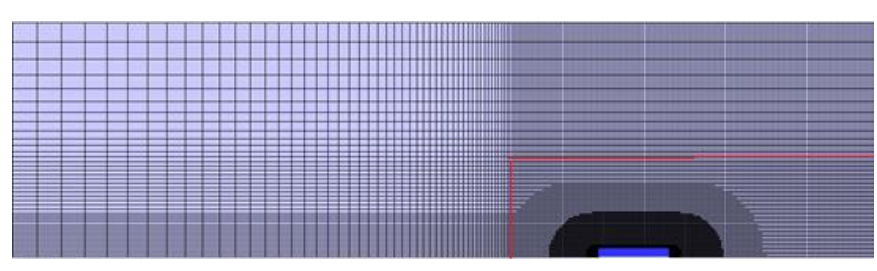

(a)

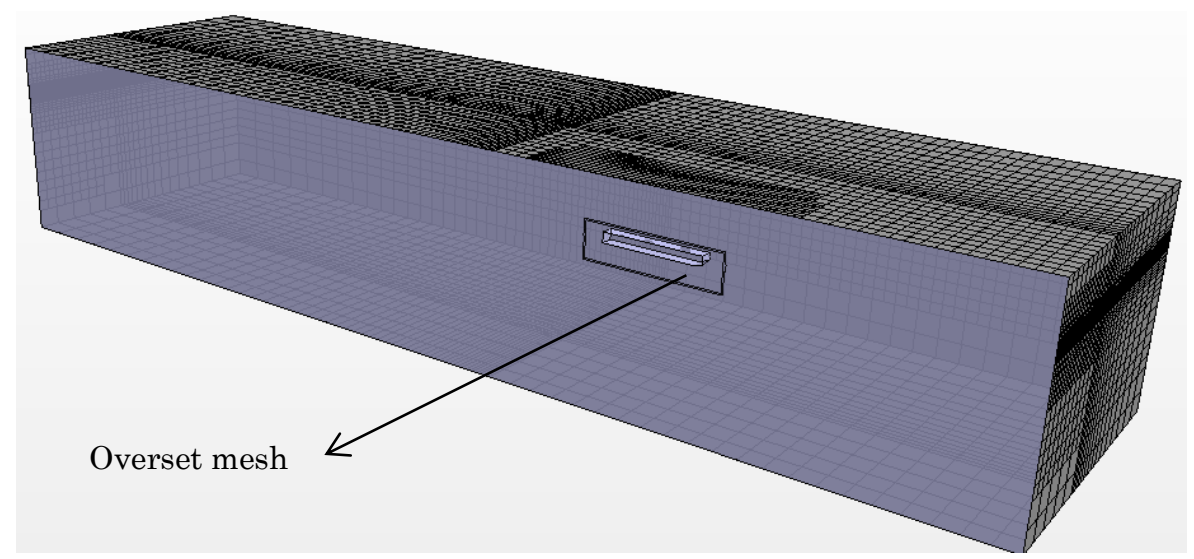

(c)

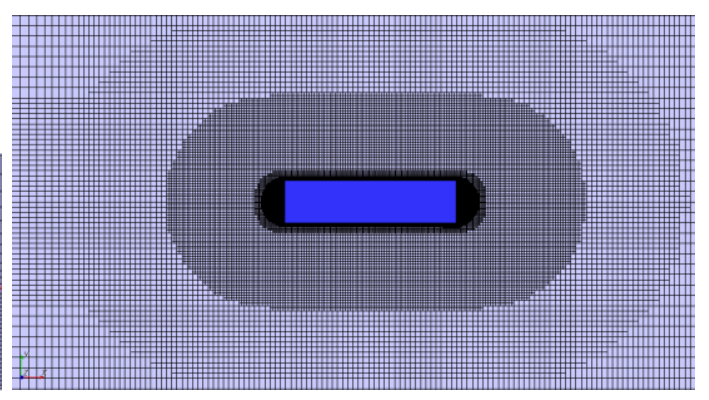

(b)

Figure 2: Mesh distribution and refinement on the free surface and body for wave period of $1.8 \mathrm{~s}(\mathrm{~N} / \mathrm{L} \approx 2)$

\subsection{Rigid barge simulations}

In order to simulate the rigid body motions of heave and pitch, a DFBI (Dynamic Fluid Body Interaction) Rotation and Translation motion is used. The DFBI motion enables the solver to compute the fluid forces and moments on the body surface due to the incident wave and solves the rigid body governing equations to reposition the body. A global earth fixed coordinate system and body-fixed coordinate system is adopted to predict the rigid body motion of the barge. The fluid forces and moments acting on the rigid body are calculated on the earth fixed coordinate system which is transformed to body-fixed coordinate system. The rigid body equations are used to calculate the velocities of the body in the local coordinate system and again converted back to earth coordinate system. The new position of the body is updated with respect to the global earth fixed axes. The orientation of the overset grid is updated after each time step (STAR-CCM+2012). A typical value of 50 time steps is specified as a body release time to allow the fluid flow to initialise and become steady before the calculation of body motions begins. To avoid the fluid forces and moments being suddenly applied on the 
body and facilitate a more robust solution by reducing oscillations, a ramp time of 10 times the release time is specified for all rigid body simulations.

Second-order upwind convection scheme was used throughout all simulations in order to accurately capture the sharp interfaces on the free surface. The maximum Inner iterations stopping criteria is the number of inner iterations that the solver performs during each time step. In general, when small time steps are used the solution changes very little from one time step to another; hence, a fewer inner iterations would suffice. If the maximum number of inner iterations selected is too low, the solutions will not converge within a time step. Based on the knowledge gained from literature ten inner iterations were deemed sufficient to produce time-accurate simulations and ensure convergence (Wilson et al. 1998 and Wilson et al. 2001).

The transient time dependent term in the governing equations of an implicit unsteady solver is computed using either a first order or a second order discretisation scheme. $1^{\text {st }}$ order temporal discretisation provides stability to the solution due to the dissipation. The disadvantage is that the time accuracy of transient behaviour will be sacrificed. Furthermore, for wave simulations the second-order provides more accurate and stable wave propagations (Peric et al. 2007 and Peric 2012). Hence, all the simulations were performed using a $2^{\text {nd }}$ order temporal discretisation.

For numerical stability, the value of local courant numbers given by $C F L=U \Delta t / \Delta x$, should be, in general, less than 1. Time step for each simulation was selected such that the Courant number at the free surface interface at all times is less than 1.0.

\subsection{Flexible barge simulations: FSI coupling}

\subsubsection{Boundary Conditions, Motion and Solver Settings}

The boundary conditions and solver settings of the CFD model are similar to those used in rigid body simulations. Lakshmynarayanana et al. (2015) observed large longitudinal drift in the cosimulation of the barge since there was no boundary condition specified in the CFD or FE model to confine the motion. This motion cannot be categorised as a surge motion but was purely a large longitudinal drift. There are a few downsides of treating the barge model in this way. Firstly, due to the unphysical drift the overset mesh will, in due course, fall out of the refinement in the background mesh permitting only to simulate about 8-10 wave periods. Secondly, the large longitudinal displacement 
will result in the body generating weaker local end waves when compared to experiments where the barge was fixed. The node close to the LCG of the barge in the FE model is prescribed with a longitudinal displacement (in $\mathrm{x}$-axis) of zero which resulted in fixing the barge in place in response to the incoming waves.

It should be noted that due the barge being very flexible the cosimulations were only stable for $\Delta t \geq 0.005 \mathrm{~s}$. It should also be noted that the use of artificial compressibility with various speeds of sound did not improve this aspect of stability. Thus, $\Delta \mathrm{t}=0.005 \mathrm{~s}$ was used for all simulations (rigid and cosimulations), which satisfies the requisite courant number. The wet 2 -node resonant period of the barge is $1.05 \mathrm{~s}$, corresponding to approximately 200 steps per period with the chosen $\Delta t$. This is relevant to large grid deformations occuring rapidly and causing negative volumes cells in the vicinity of the barge. (Richter \& Wick 2013) compares the time steps per oscillation required for a standalone CFD and FSI cosimulations on a flow around an elastic beam. It was reported that while the CFD simulations requires less than 10 time steps per oscillation the cosimulated problem required 100 time steps per period of the first flexible mode, a requirement which doubly satisfied in the current cosimulations.

The grid flux term represents the ratio of volume swept due to the movement of cell faces from one time step to the next time step. In the cosimulation, the grid flux corresponds to the response of the fluid grid to the structural velocities of the deforming body. In the present simulations, the URF (under relaxation factor) for this term is lowered from a default value of 1.0 to 0.8 , implying that the fluid response to structural response is slightly reduced by a fraction commensurate to the URF. This was done to provide stability as many attempts with a higher grid flux URF resulted in quick pressure divergence. The number of exchanges per time step is defined so that the calculated cosimulation displacement has converged which is carried out by monitoring the cosimulation residuals. Bloxom (2014) in his study of predicting the forces and displacements of a flexible bow seal used 20 inner iterations with 4 exchanges per time step resulting in 5 inner iterations per time step. Camilleri et al. (2015) also recommend similar coupling parameters for the constant velocity impact of a flexible wedge in water. In the present investigations, a total of 15 inner iterations per time step and 3 exchanges were performed i.e., for every data exchange a total of with 5 inner iterations take place. The cosimulation residuals were checked in all the simulations carried out in the present study and they decreased by 5-7 orders after the chosen total number of iterations and exchanges. 


\subsubsection{Finite Element Model}

The material and geometric properties of the B31 beam elements are modelled in line with model data, shown in Table 1. 48 B31 elements of equal length are used to model the backbone of the barge. The material data and geometry specification is given in Table 4.

Table 4: Material and Geometric data of FE model

\begin{tabular}{cc}
\hline Property & Value \\
\hline Material & Steel \\
Density & $7850 \mathrm{~kg} / \mathrm{m}^{3}$ \\
Young's Modulus & $210 \times 10^{9} \mathrm{~N} / \mathrm{m}^{2}$ \\
Poisson's ratio & 0.3 \\
Length & $2.445 \mathrm{~m}$ \\
Cross-Section of beam & $1 \mathrm{~cm} \times 1 \mathrm{~cm}$ \\
Number of nodes & 49 nodes \\
\hline
\end{tabular}

The investigations conducted in this paper only deal with the vertical responses of a flexible barge. Timoshenko (B31) linear beam elements with six degrees of freedom per node are used to represent the structure. It should be noted, however, that the influence of effective shear area and rotatory inertia were ignored. A beam profile is defined by specifying the area and moments of inertia along the cross-sectional axes of the beam. The hull surface is modelled using 4-node quadrilateral elements SFM3D4, as mentioned in section 2.2. The surface elements in Abaqus have no bending or transverse stiffness, but may have mass/unit area (not used for the current simulation) and they can be used to transmit in-plane forces. They behave like membrane elements with zero thickness.

The dummy surface elements are linked to the nodes on the beam elements using kinematic coupling constraints shown in Figure 3. All six degrees of freedom are constrained in the kinematic coupling of beam nodes and the dummy surface, in the sense that the beam deformations are imparted on to the barge hull. The total mass of the barge is distributed on the beam elements as lumped masses. The mass of each section of the barge, which encompasses the caisson, square rod and bracing equipment, is aggregated as the analogous beam section mass and the lumped mass.

For the 2-D hydroelasticity analysis the barge is represented as a non-uniform beam comprising 48 sections, to achieve consistency with the finite element model. The mass 
distribution, moment of inertia for each segment, is similar to the finite element model. The effects of shear deformation and rotary inertia are neglected. No structural damping is used in either of the numerical models.
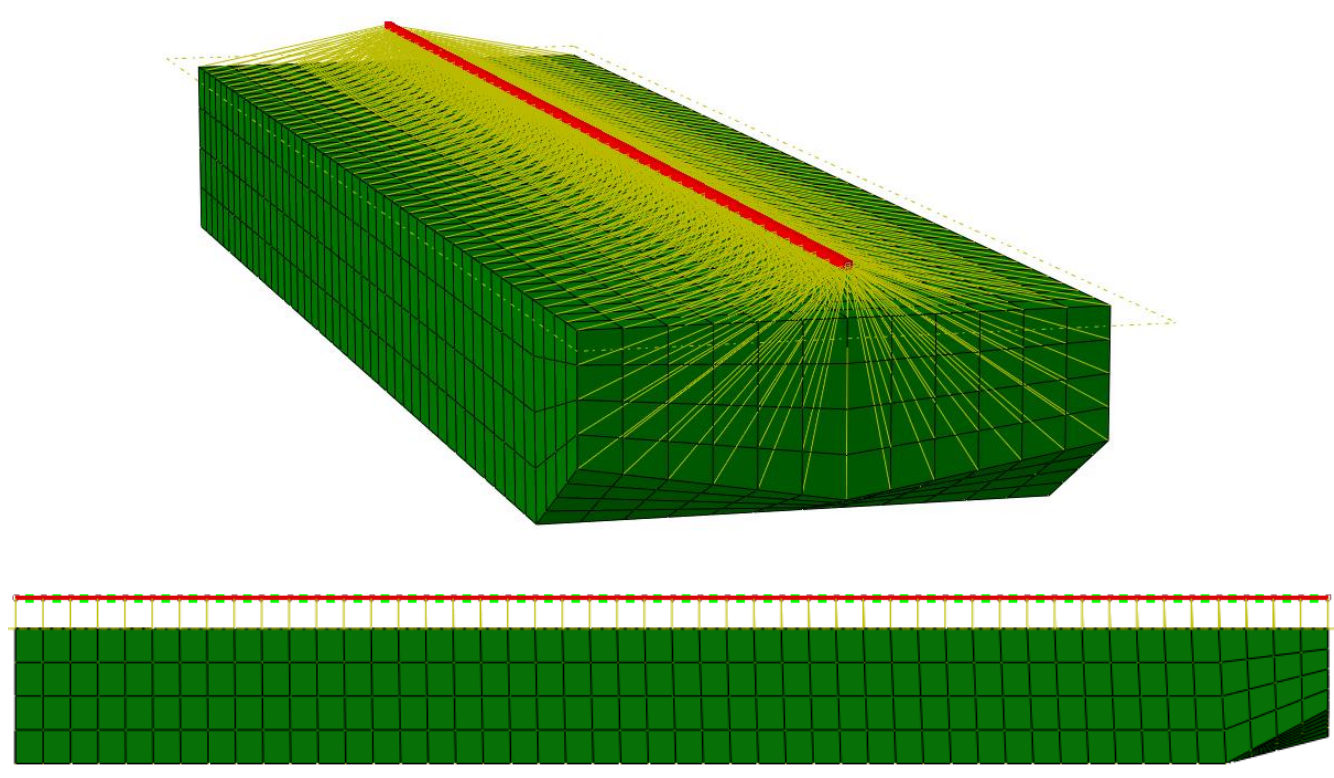

Figure 3: Finite Element mesh with beam and dummy surface linked using kinematic coupling

\section{Results and Discussion}

\subsection{Wave elevation monitoring}

The forcing function in the case of the barge in waves is the incident wave and, hence, it is important to monitor the wave elevation in front of the barge. Assuming linearity, the motion and loads calculated are presented as transfer functions per wave amplitude, called Response Amplitude Operators (RAO). Wave elevations were recorded at distance Lpp in front of the barge. The time history of the wave elevations revealed very little wave dissipation, and maximum decrease in wave height was around 5-6\% as the simulation progressed. Average wave amplitude over the last stable 15 wave periods was used to calculate the RAOs, noting that the simulation was run for 20 periods. Figure 4 shows the time history of wave elevation recorded for the $1.6 \mathrm{~s}(\lambda=3.996 \mathrm{~m})$ wave plotted against the theoretical first order wave. 


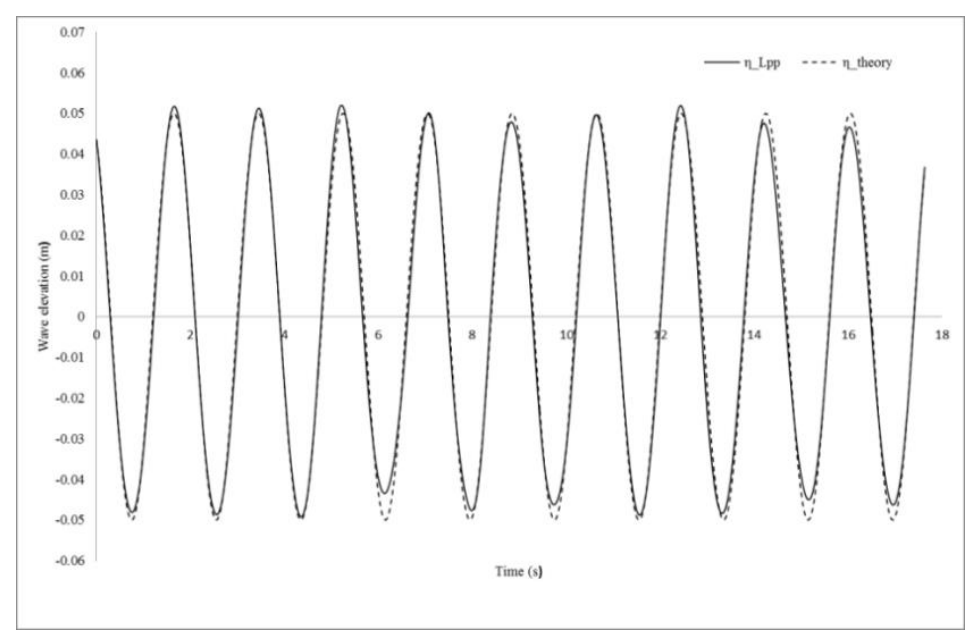

Figure 4: Wave elevation at $\mathrm{L}_{\mathrm{pp}}$ in front of the barge for $\mathrm{Tw}=1.6 \mathrm{~s}$ wave.

\subsection{Verification assessment}

Grid convergence studies for the flexible barge are presented in this section. ASME (2008) standards recommends a minimum grid refinement factor (coarser mesh /finer mesh $=r_{k}$ ) greater than 1.3 should be maintained so that discretisation error can be differentiated from other sources of error, such as iterative error, round-off error etc. Roache (1998) suggested a grid convergence index (GCI) which is derived from the generalised Richardson's extrapolation theory to report the error estimation of different grids used for convergence studies. The GCI indicates a measure of error between the solutions from the asymptotic value.

The grid used in the simulations presented in Section 4.3 is considered as coarse grid. Medium and fine grids, shown in Table 5, were generated from the coarse grid using a constant refinement ratio $\left(\mathrm{r}_{\mathrm{k}}\right)$ of 1.3. ASME (2008) describes a systematic step-by-step procedure and the parameters to be reported to conduct error and uncertainty study due to the discretization in CFD computations. Two frequencies $(\omega=5.24,6.28 \mathrm{rad} / \mathrm{s}$, $\mathrm{H}_{\mathrm{w}}=100 \mathrm{~mm}$ ) were chosen to conduct convergence studies. Large motions and responses were observed in these two wave conditions which in-turn is likely to induce highest numerical errors making it the worst case scenarios. Two integral variables (first harmonic of vertical force on the barge $\mathrm{F}_{\mathrm{z}}$ and bending moment amidships VBM) and a point variable (total vertical displacement amidships $\mathrm{u}_{\mathrm{z}}$ ) is used in the verification studies. The verification parameters for the variables are given in Table 6 .

Table 5: Three different grid levels used for verification studies and the total grid count. 


\begin{tabular}{ccc}
\hline Grid Level & \multicolumn{2}{c}{ Global Cell count } \\
& $5.24 \mathrm{rad} / \mathrm{s}$ & $6.28 \mathrm{rad} / \mathrm{s}$ \\
\hline Coarse & 3.15 million & $6.8 \mathrm{million}$ \\
Medium & 6.62 million & 13.45 million \\
Fine & 12.2 million & 24 million \\
\hline
\end{tabular}

Generally, a monotonic grid convergence was achieved for the variables at the two frequencies. The apparent orders for $\omega=5.24 \mathrm{rad} / \mathrm{s}$ were close to the order of the unsteady solver, however, $\omega=6.28 \mathrm{rad} / \mathrm{s}$ show higher orders of accuracy. Higher orders of accuracy do not necessarily imply higher numerical accuracy, but indicate that finer meshes converged rapidly when compared to the coarse mesh. Nevertheless, such sporadic orders are not unrealistic and the values presented here are reasonable when compared with similar unsteady problems investigated by Weymouth et al. (2005), Wilson et al. (2001) and Carrica et al. (2006). A low percentage of GCI for both fine and medium meshes indicate that the numerical results are close to the asymptotic value. The percentage of errors and uncertainties are much lower for the VBM and the vertical displacement when compared to the first harmonic vertical force acting on the barge. The difference in pressure at around amidships for all the three grids is relatively small; consequently the differences calculated in the bending moment are small. However, refinement of grid around the body changes the diffracted wave profile around the barge which results in variations in pressure, especially towards the ends of the barge. The vertical force is calculated by integrating the total pressure on the body which could vary moderately in magnitude for different grids, if not significantly. This could be one of the main reasons why the verification parameters are comparatively higher for the vertical force. From the results presented in Table 6 it can be concluded that the coarse mesh is computationally efficient as well as accurate to conventional engineering requirements. 
Table 6: Grid Convergence verifications parameters for three variables namely the vertical displacements amidships, vertical force and the vertical bending moment amidships. Superscripts 1, 2 and 3 indicate fine, medium and coarse mesh, respectively.

\begin{tabular}{|c|c|c|c|c|c|c|}
\hline$\omega$ & $\begin{array}{l}\text { variable } \\
\text { for } \\
\text { verificat }\end{array}$ & $\begin{array}{l}\text { Approximate } \\
\text { relative } \\
\text { error } e_{a}^{21}\end{array}$ & $\begin{array}{l}\text { Extrapolated } \\
\text { relative } \\
\text { error } e_{\text {ext }}^{21}\end{array}$ & $G C I_{\text {fine }}^{21}$ & $G C I_{\text {medium }}^{32}$ & $\begin{array}{l}\text { Apparent } \\
\text { order p }\end{array}$ \\
\hline \multirow{4}{*}{$5.24 \mathrm{rad} / \mathrm{s}$} & $\mathrm{u}_{\mathrm{z}}$ & $2.613 \%$ & $3.762 \%$ & $4.532 \%$ & $5.846 \%$ & 2.069 \\
\hline & $\mathrm{F}_{\mathrm{z}}$ & $5.559 \%$ & $9.344 \%$ & $10.6 \%$ & $6.131 \%$ & 1.91 \\
\hline & VBM & $0.923 \%$ & $1.88 \%$ & $2.307 \%$ & $1.524 \%$ & 1.5 \\
\hline & $\mathrm{u}_{\mathrm{z}}$ & $1.713 \%$ & $0.433 \%$ & $0.539 \%$ & $2.635 \%$ & 6.1 \\
\hline \multirow[t]{2}{*}{$6.28 \mathrm{rad} / \mathrm{s}$} & $\mathrm{F}_{\mathrm{z}}$ & $5.56 \%$ & $2.191 \%$ & $2.68 \%$ & $0.708 \%$ & 4.866 \\
\hline & VBM & $1.163 \%$ & $0.127 \%$ & $0.159 \%$ & $1.59 \%$ & 8.8 \\
\hline
\end{tabular}

\subsection{Modal Analysis}

Modal analysis was performed in Abaqus using Block Lancozs (Dassault Systèmes 2013) eigenvalue extraction method. The dry (or invacuo) natural frequencies and mode shapes obtained in Abaqus were compared against calculations performed using finite difference method applied to a non-uniform beam (Bishop et al. 1977), to ascertain the accuracy of structural modelling. The dry hull natural frequencies for the first 5 flexible modes are shown in Table 7.

Table 7: Symmetric Dry Hull natural frequencies (rad/s)

\begin{tabular}{cccc}
\hline Mode & Abaqus & $\begin{array}{c}\text { Finite difference } \\
\text { method(2-D) }\end{array}$ & \% error \\
\hline 2-node & 6.01 & 6.03 & 0.34 \\
3-node & 16.43 & 16.49 & 0.37 \\
4-node & 32.00 & 31.10 & 2.8 \\
5-node & 52.66 & 52.73 & 0.13 \\
\hline
\end{tabular}




\subsection{Vertical displacement in waves}

The RAO of vertical displacements, calculated at all six locations used by Remy et al. (2006), are illustrated in Figure 5. In this figure CFD denotes results using the cosimulation, CFD_rigid the Star-CCM+ predictions, Mars the 2-D hydroelasticity and Mars_rigid the 2-D strip theory predictions. The experimental measurements of Remy et al (2006) for $\mathrm{Hw}=100 \mathrm{~mm}$ are denoted by $\operatorname{Remy}(2006)$. The 2 -D rigid body response is obtained from the 2-D hydroelastic code, only using the principal coordinates of heave and pitch in the modal summation.

Comparing the rigid body displacements, i.e. CFD vs 2 -D potential flow, it can be seen that the numerical predictions at amidships (Point7) closely match each other for all frequencies. There is reasonable agreement between the predicted rigid body displacements at other locations with exception towards the forward end of the barge (points 1 and 3), as well as the stern. The RAOs are larger in the CFD simulations than 2-D linear predictions towards the bow of the barge. At the forward section of the barge, strong bow waves were seen to develop in the CFD simulations from a wave frequency of $3.9 \mathrm{rad} / \mathrm{s}$ and upwards. With increase in frequency, diffraction becomes more dominant resulting in strong localized bow waves, shown in Figure 6(a) \& Figure 7(a). At point 12, close to the stern $(0.19 \mathrm{~m}$ in front of AP), the RAOs of the vertical displacement predicted by CFD_rigid at $3.926 \mathrm{rad} / \mathrm{s}$ are larger than 2-D linear predictions. The contour plot at this frequency shows strong bow and stern waves influenced by pitch motion, as seen in Figure 6(a). The reason for the discrepancy between the numerical predictions at the bow and stern sections of the barge is largely due to the influence of strong localised wave systems, not very well predicted using a linear potential flow theory. The predictions using CFD is considered more reliable in this case, since it accounts for the nonlinear interactions and 3-D effects between the wave and body.

The total vertical displacements for the flexible barge comprise both rigid body and distortional displacements. RAOs from cosimulation, also shown in Figure 5, compare well with the experimental measurements at most locations, albeit some differences were noted at higher frequencies. In general, the current method under-predicts the displacements at higher frequencies, specifically towards the bow. The maximum percentage error is observed at Point $5(1.625 \mathrm{~m}$ from aft) at $6.28 \mathrm{rad} / \mathrm{s}$, about $36 \%$. For 
the same frequency the error between 2 -D predictions and measurements is about $60 \%$. The relative differences are highest at wave frequencies $6.28 \mathrm{rad} / \mathrm{s}$ and $6.98 \mathrm{rad} / \mathrm{s}$. The wet natural frequency in water measured in experiments from decay tests was $6.7 \mathrm{rad} / \mathrm{s}$. The maximum discrepancy is also occurring at frequencies in the vicinity of the wet natural frequency. This indicates that the computations are sensitive around the resonance region. Nonetheless, the grid convergence index reported in Table 6 at the above frequencies indicates that the differences are not emerging due to discretisation errors.

The gaps between the caissons in the experimental model are not considered in the CFD/FEA model or in the 2-D hydroelasticity. The absence of gaps in the numerical model could result in slightly different hydrodynamic properties, namely added mass and fluid damping, compared to the real situation. The absence of structural damping in the numerical models could also have an effect in the predictions, especially in the vicinity of the natural frequency. (Kim et al. 2013) had introduced artificial damping force on the barge and found significant difference in the vertical displacements end locations. They tuned the damping force to match the displacements at the ends of the barge with experiments.

Again with increase in frequency, the disparity between the two numerical predictions, for the barge treated as rigid or flexible, increases as we move towards the bow. Of the two numerical methods, the cosimualtion shows much better agreement with experimental data. Figure 6(b) and Figure 7(b) illustrate strong diffraction effects in flexible body motions as the wave frequency increases. At $3.92 \mathrm{rad} / \mathrm{s}$, there is a marked difference between the wave radiation contour of the rigid and flexible body simulations. In the case of rigid barge, strong localised bow and stern wave systems are prevalent; however, the flexible barge tends to deform following the wave, this results in very weak or rather no localised waves. Accordingly, the agreement between the co-simulated numerical predictions is better at lower frequencies at the extremities of the barge. The motion of the barge, above $3.92 \mathrm{rad} / \mathrm{s}$, creates strong free surface disturbances for both rigid and flexible cases.

Comparing the present predictions for rigid and flexible barge models (see Figure 5) at the bow and stern (Points 1, 3, 12), we can observe an interesting trend. The influence of localised wave systems at $3.92 \mathrm{rad} / \mathrm{s}$, absent in the flexible barge computations, results in larger rigid body displacements. As the wave frequency increases, the diffraction effect is existent in both rigid and flexible body simulations, although, flexibility starts 
to play a more dominant role producing higher distortions leading to large RAOs. This behaviour gets more prominent around the 2-node wet frequency exhibiting 34\% difference between rigid and flexible displacements at the bow.
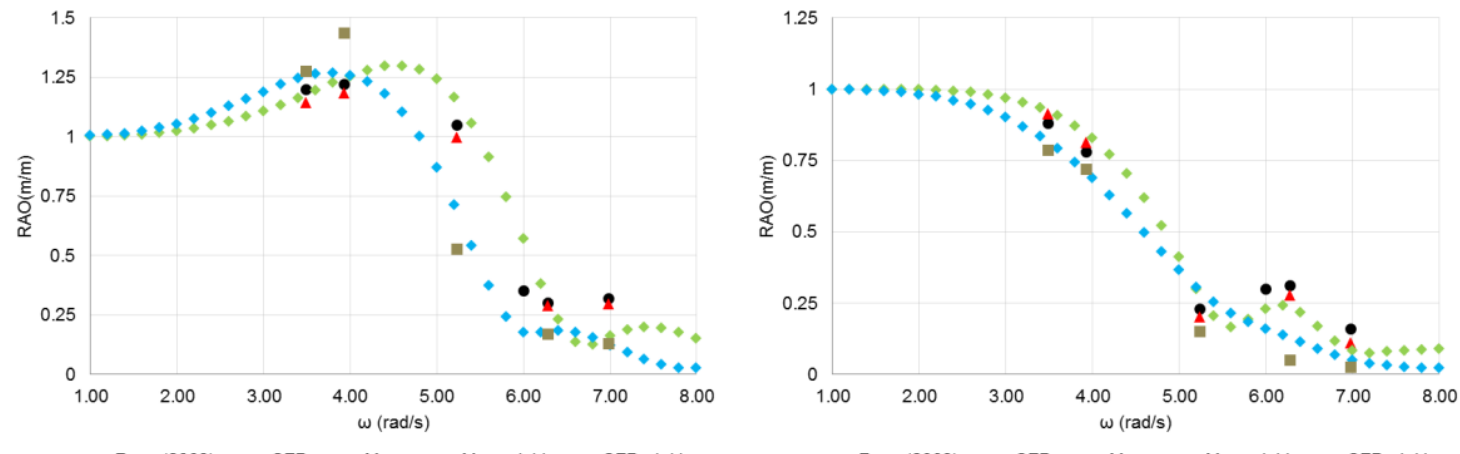

Response at Pt 12
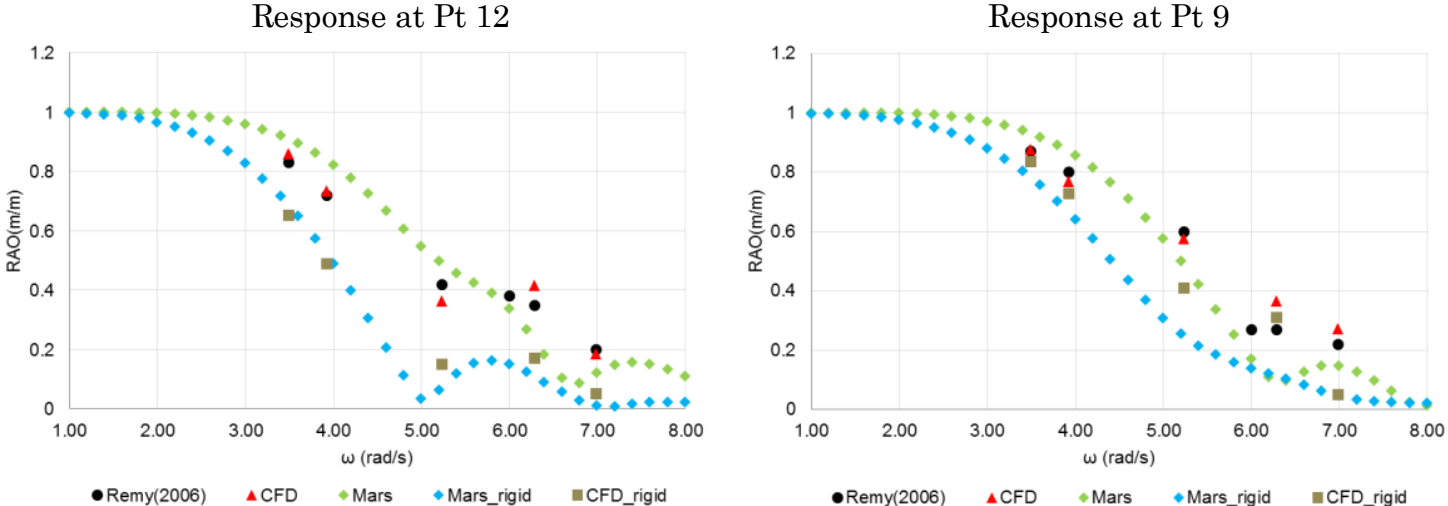

Response at Pt.7

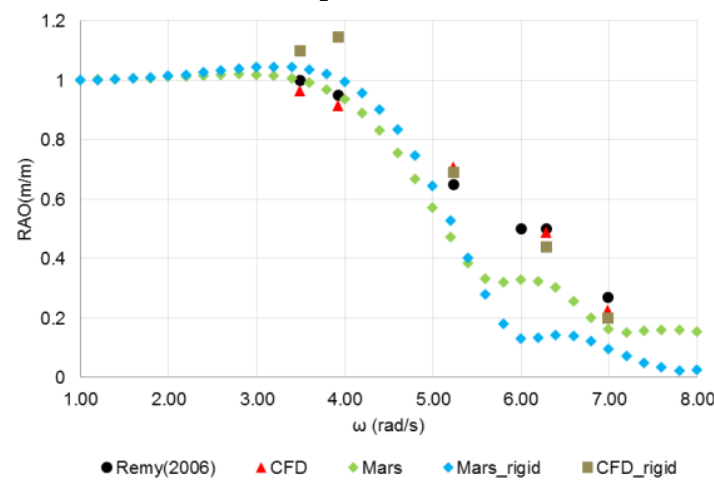

Response at Pt. 3

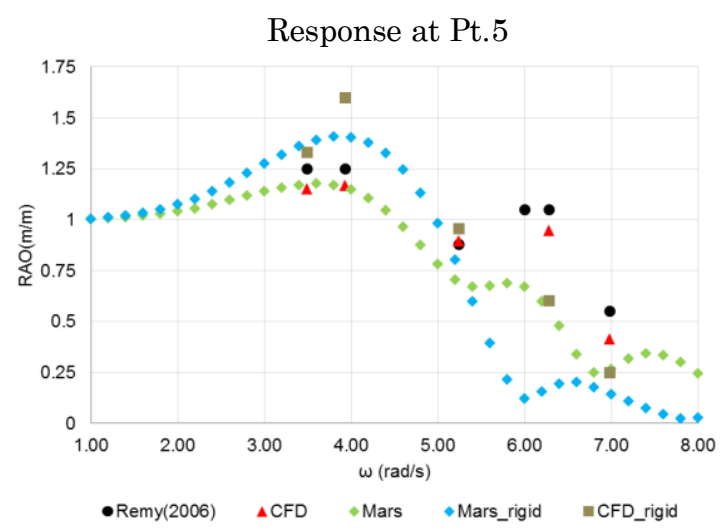

Response at Pt. 1

Figure 5: RAOs of vertical displacements along the barge, point 12 near the stern and point 1 near the bow, for both rigid and flexible body analyses

It is clear from this validation exercise that the present cosimulation method is capable of predicting the displacements of a very flexible structure to a good degree of accuracy. When compared to linear methods, predictions taking into account the nonlinearities are well suited to such flexible structures which introduce significant free surface disturbances at certain frequencies. Omitting, such nonlinearities can result in under predictions when compared to actual measurements; hence, the CFD methods are more 
suited. The CFD simulation based methods also give insights into interesting flow features which aid in explaining the agreements and discrepancies better. Finally, rigid body approximations are not well suited for a very flexible structure and can result in severe under prediction, especially in the vicinity of the natural frequencies.

The rigid body displacements calculated using the 2-D method and the CFD show good congruence at amidships suggesting that the heave motion is well predicted by the two methods. The agreement is also good at most locations, nevertheless the differences start to emerge towards the ends of the barge at certain wave frequencies where the motion of the barge instigate strong end waves radiated out of the body resulting in under prediction of 2-D potential flow displacements. In the case of the flexible simulations, the two numerical methods predict generally well when compared to the measurements, except again towards the ends of the barge where at higher frequencies the cosimulation performs better. This outlines the importance of nonlinearities excited due to the motion and localised waves that could have a significant effect and result in under prediction when carrying out 2-D potential flow predictions.

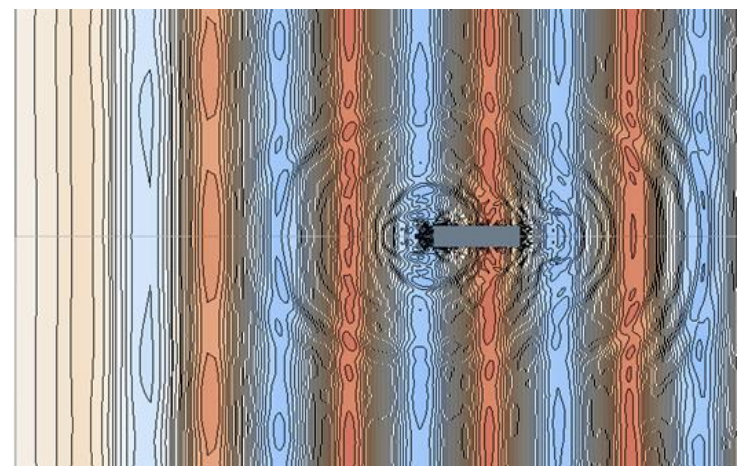

(a)

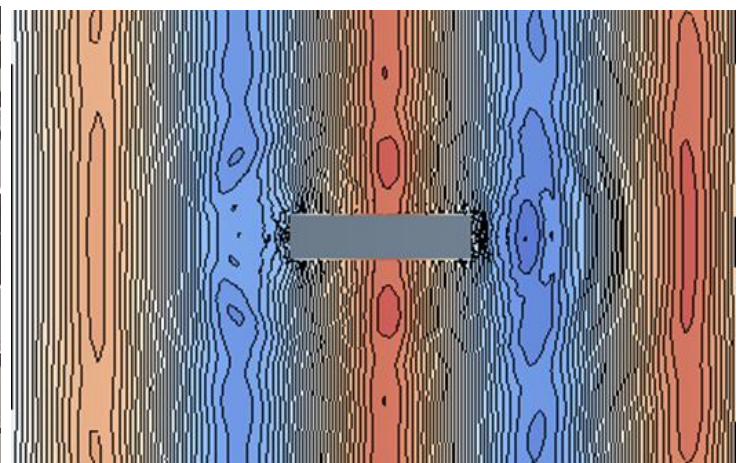

(b)

Figure 6: Instantaneous wave contour around the rigid body (a) and flexible (b) at 11.5s for wave frequency of $3.926 \mathrm{rad} / \mathrm{s}$

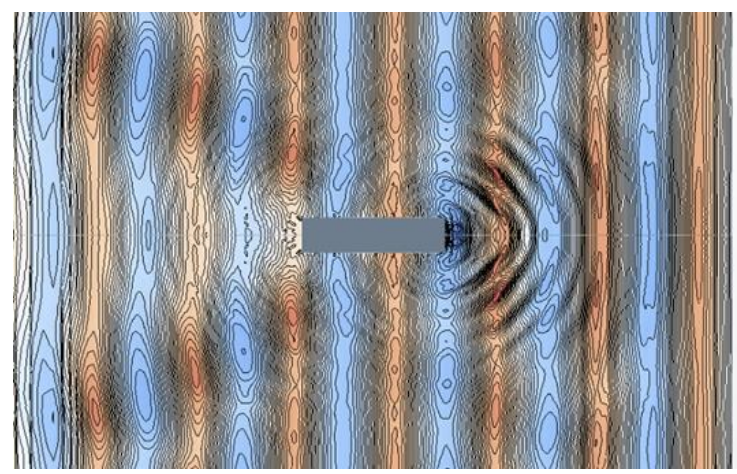

(a)

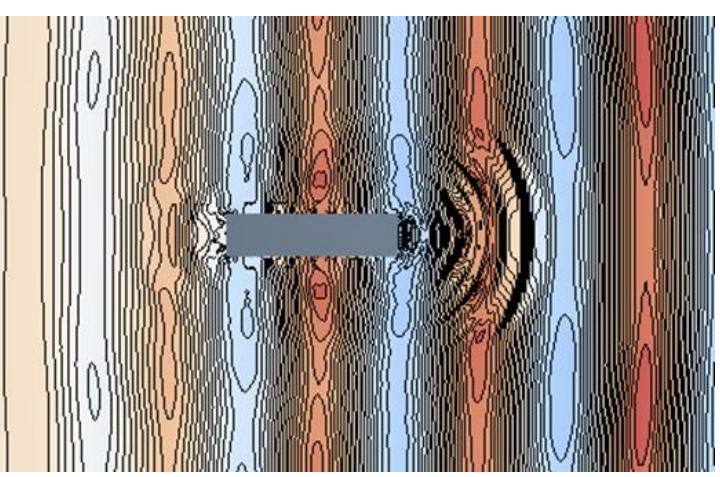

(b)

Figure 7: Instantaneous wave contour around the rigid body (a) and flexible (b) at 9. 5s for wave frequency of $6.28 \mathrm{rad} / \mathrm{s}$ 


\subsection{Vertical bending moments in waves}

RAOs of VBM are shown in Figure 8 , at locations $\mathrm{x} / \mathrm{L}=0.5$ and 0.66 together with comparisons from 2-D linear hydroelastic analysis. The displacements plots at the corresponding locations are also presented in the figure to facilitate comparing trends between displacements and bending moments. Apart from the wave frequencies shown in Table 2 the RAOs of VBM were calculated for three additional wave frequencies $(\omega)$ corresponding to $4.5,5.8$ and $6.7 \mathrm{rad} / \mathrm{s}$. In the $\mathrm{VBM}$ plots, the first peak, which corresponds to ship-wave matching region $(\lambda / \mathrm{L}=1.0)$, is observed around $5.5 \mathrm{rad} / \mathrm{s}$. Comparing the RAOs of VBM predicted by the numerical methods, it is obvious that the general trend of the plots for the frequencies investigated is similar. Nevertheless, the relative magnitude of RAOs shows significant differences, especially in the vicinity of the resonant frequency, as illustrated in Table 8. Firstly, let us study the effect of change in the location on the bending moment, at individual wave frequencies. Aside from wave frequencies, $\omega=5.25 \mathrm{rad} / \mathrm{s}$ and $6.28 \mathrm{rad} / \mathrm{s}$, the relative differences at other wave frequencies are moderate, if not considerably low. There is also a good agreement in vertical displacements between the numerical predictions at these frequencies.
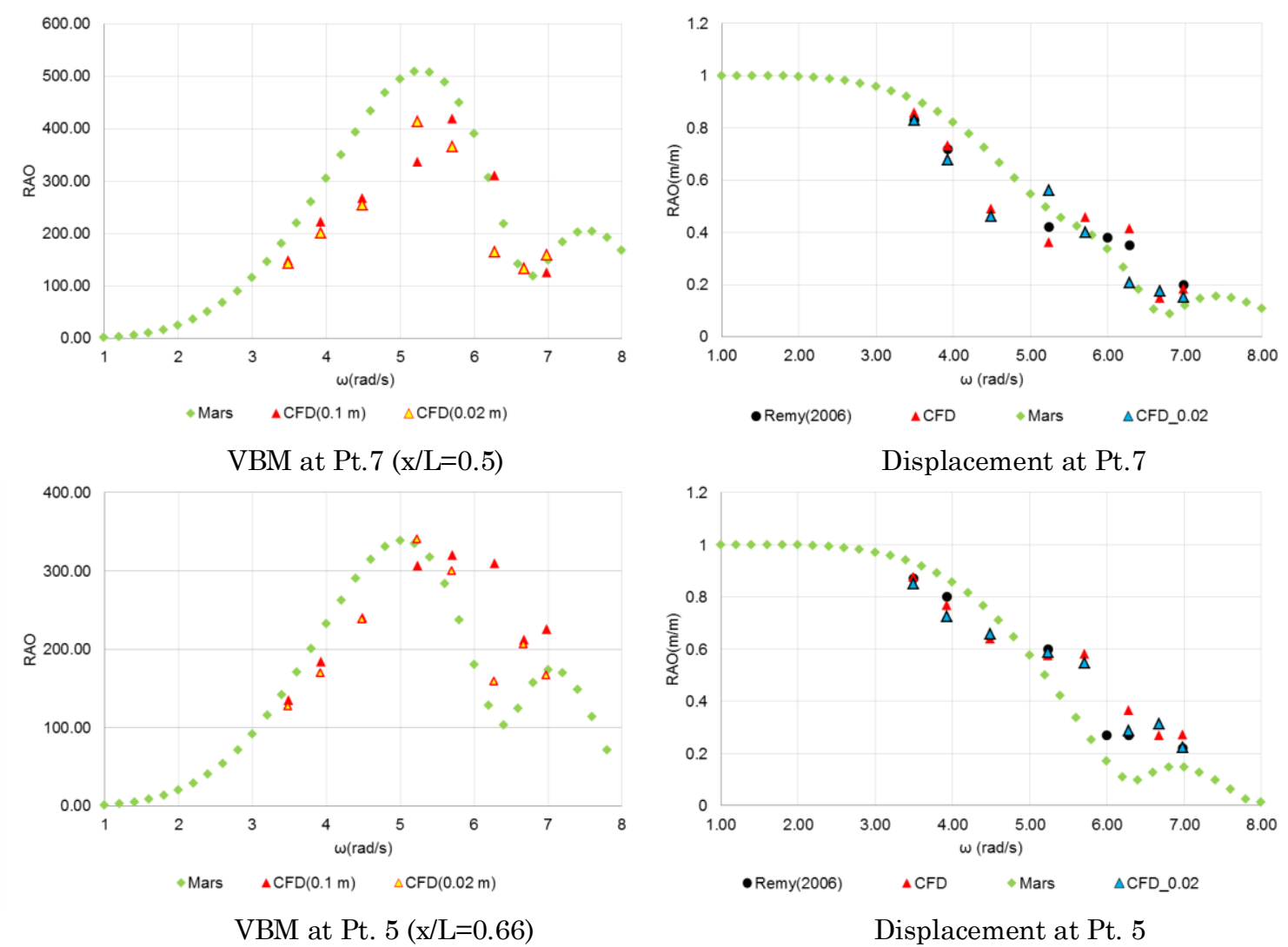

Figure 8: RAOs of VBM and vertical displacement along the barge at $\mathrm{x} / \mathrm{L}=0.5$ and 0.66 . 
The RAOs of VBM amidships at the first peak $(5.25 \mathrm{rad} / \mathrm{s})$ is lower in the coupled simulations by about $34 \%$ in comparison to 2 -D hydroelastic predictions. In general, the VBM at this wave frequency is under-predicted by the present method at all locations. Referring to the vertical displacements, there is mismatch between the predictions of the two numerical methods; however, the predictions of the present method are closer to the experimental measurements. Although, this does not establish the fact that bending moment predicted by the coupled simulations are closer to the true vertical bending moments, it is definitely encouraging since we observe a general similarity between predicted displacements and bending moments. The main reason for the discrepancy is thought to be the influence of nonlinear hydrodynamic interaction between the radiated waves and the incoming waves. Another abnormality noted in Table 8 is for Point 5 at $\omega=6.28 \mathrm{rad} / \mathrm{s}$, where $\mathrm{VBM}$ predicted by the coupled simulations is nearly 1.4 times more than the 2-D predictions. A trough occurs in the 2-D prediction at this location and frequency which is not captured by the coupled simulations. The difference in vertical displacements is also high between the numerical predictions (36\%), although the coupled method is closer to experiments.

Table 8: Relative percentage error of VBM amidships between 2-D and coupled simulations (wave heights given in Table 2). The percentage values in italics are for differences between 2 -D and cosimulation for a wave height of $0.02 \mathrm{~m}$.

\begin{tabular}{|c|c|c|c|c|c|c|c|c|}
\hline Location & & & & $\omega$ (wav & lency) & & & \\
\hline $\mathrm{rad} / \mathrm{s}$ & 3.49 & 3.93 & 4.49 & 5.24 & 5.71 & 6.28 & 6.68 & 6.98 \\
\hline $\begin{array}{c}\text { Pt. } 5 \\
(\mathrm{x} / \mathrm{L}=0.5)\end{array}$ & $17 \%$ & $17 \%$ & $35 \%$ & $34 \%$ & $9 \%$ & $3 \%$ & $5 \%$ & $10 \%$ \\
\hline $\begin{array}{c}\text { Pt. } 7 \\
(x / L=0.66)\end{array}$ & $11 \%$ & $12 \%$ & $15 \%$ & $8 \%$ & $23 \%$ & $140 \%$ & $50 \%$ & $28 \%$ \\
\hline Pt. 5 & $21 \%$ & $25 \%$ & $35 \%$ & $19 \%$ & $20 \%$ & $40 \%$ & $6 \%$ & $8 \%$ \\
\hline Pt. 7 & $11 \%$ & $19 \%$ & $15 \%$ & $2 \%$ & $15 \%$ & $22 \%$ & $47 \%$ & $5 \%$ \\
\hline
\end{tabular}

From these responses, it can be noted that although qualitatively the agreement between the numerical predictions is good, there are large quantitative discrepancies. The above investigations unveil the possibility of effect of nonlinearities in motions and responses due to the hydrodynamic interactions. The main focus of the validation of the 
cosimulation is the comparison of calculated and measured displacements at various locations along this barge. Nevertheless, full demonstration of the working of the cosimulation approach used required the evaluation of the bending moments and verification of their order of magnitude against a method available to the authors, as well as one shown to be practically reliable for conventional ships, namely the 2-D hydroelasticity. The measured total vertical displacements and the cosimulation results compare well. However, discrepancies were noted between the 2-D hydroelasticity predictions and experimental measurements for the total vertical displacements, especially at frequencies where there was significant free surface disturbances observed in the simulations in the range between 4 and $6 \mathrm{rad} / \mathrm{s}$, as was illustrated in Figure $6 \&$ Figure 7 of this paper (also note that approximately $5 \mathrm{rad} / \mathrm{s}$ corresponds to ship length $=$ wave length). Having linear predictions as the only comparator in circumstances where we expect nonlinear $(\mathrm{H} / \mathrm{L} \approx 1 / 25)$ contributions is unreasonable. Lack of experimental measurements or other references make it difficult to reliably conclude as to which method is more accurate. The coupled problem of the barge using the present method can be assumed to be linear by carrying out computations in smaller wave heights. Comparisons with linear potential flow using such an assumption can be considered more suitable.

\subsection{Influence of nonlinearities}

To get a better insight into the dissimilarities and make the comparisons more consistent, the computations were carried out using a less steep wave ratio of $\mathrm{H} / \mathrm{L} \geq 100$ which corresponds to a wave height of $20 \mathrm{~mm}(\mathrm{H} / \mathrm{L} \approx 1 / 122)$. The cosimulation was investigated for all the frequencies shown in Figure 8 and the bending moments were compared with the 2-D predictions.

Figure 8 shows the RAOs of VBM for the smaller wave height, denoted as CFD_0.02. The simulation results for different wave heights at lower frequencies show small differences. At lower frequencies, the free surface disturbances are practically nonexistent (as was also observed in Figure 6 (a)) for the two wave heights which can be identified in Figure 9 showing wave contour plots at the same time instances. However, at the resonant condition, see Figure 10, the radiated waves disappears as the wave height decreases. This is also reflected in the RAOs of responses, as we notice a better agreement between Mars and CFD_0.02. The calculated VBM using the cosimualtion at both locations for $\omega=6.28$ and $6.98 \mathrm{rad} / \mathrm{s}$ now exhibit very good agreement with the $2-\mathrm{D}$ 
predictions. Table 8 shows the relative difference in bending moment predicted by the numerical methods. There is an improvement in the bending moment predicted by the cosimulation at the ship-wave matching region.

We attempted to reduce the influence of "nonlinear" effects by reducing the wave height from $\mathrm{L} / \mathrm{H}=25$ to $\mathrm{L} / \mathrm{H}=125$, corresponding to wave heights of 0.1 and $0.02 \mathrm{~m}$, respectively. As can be observed from the vertical displacements at point 5 and 7 shown in Figure 8, which include cosimulation predictions for both wave heights, the differences between cosimulation and 2D hydroelasticity persist for either wave height. This shows that the cosimulation predictions for this very flexible barge FSI are capturing phenomena not observed in linear potential flow analysis in the frequency range between 4 to $6 \mathrm{rad} / \mathrm{s}$. We also refer to these as "nonlinear" effects, probably more related to the large flexibility of the barge.

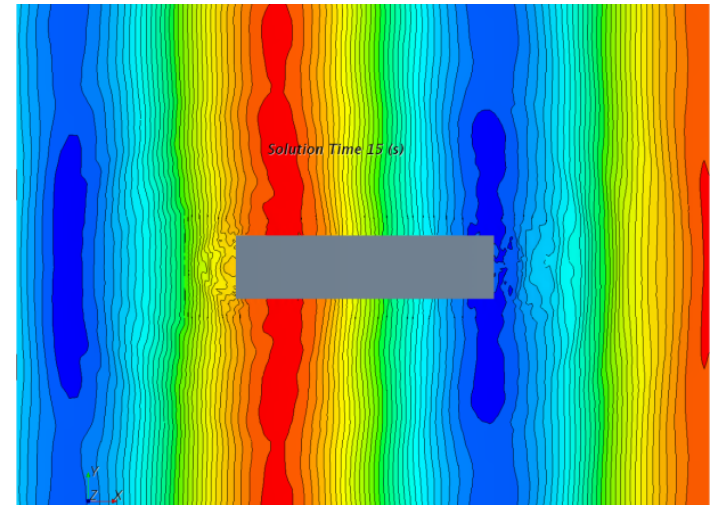

(a)

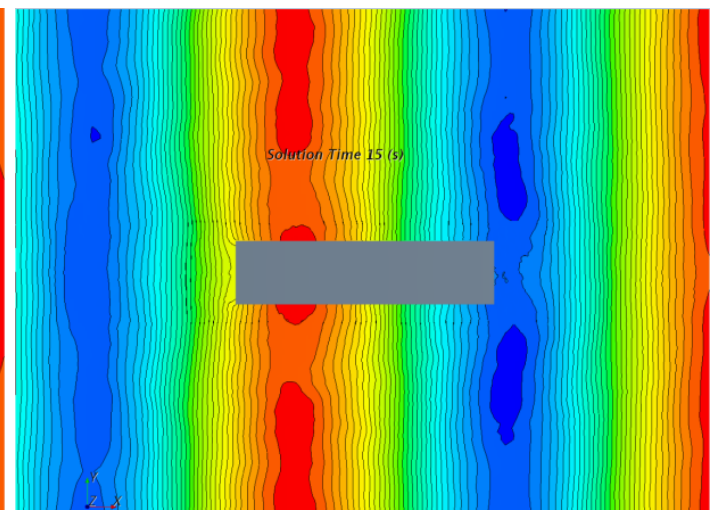

(b)

Figure 9: Instantaneous wave contour around the flexible body for wave height (a) $0.1 \mathrm{~m}$ and (b) $0.02 \mathrm{~m}$ at $15 \mathrm{~s}$ wave frequency of $3.926 \mathrm{rad} / \mathrm{s}$

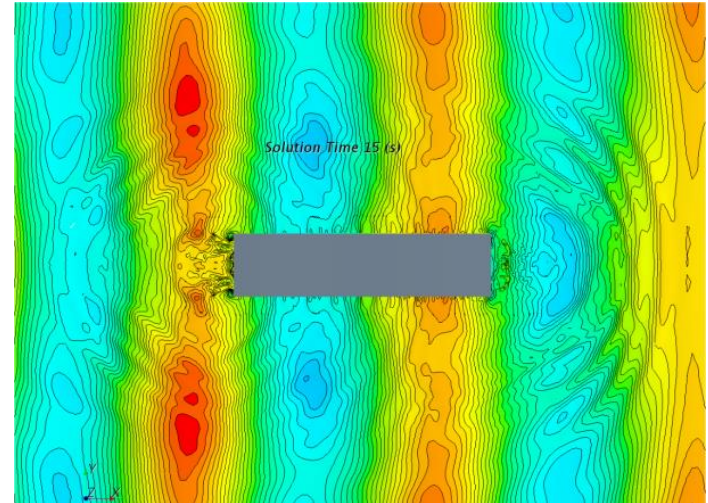

(a)

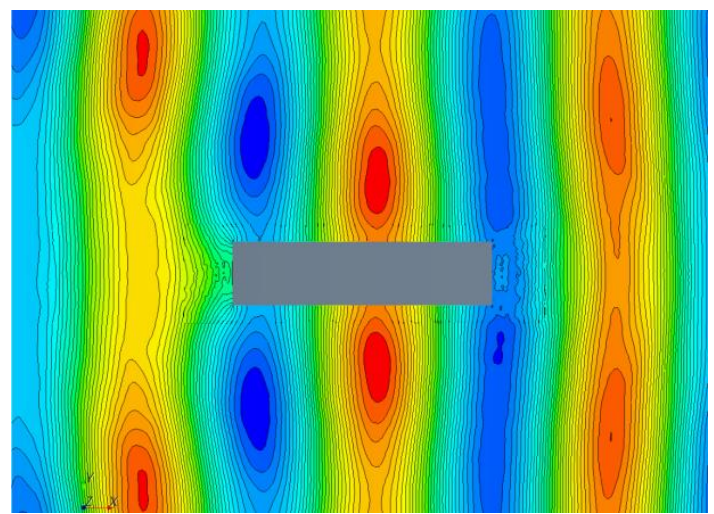

(b)

Figure 10: Instantaneous wave contour around the flexible body for wave height (a) $0.1 \mathrm{~m}$ and (b) $0.02 \mathrm{~m}$ at $15 \mathrm{~s}$ wave frequency of $5.235 \mathrm{rad} / \mathrm{s}$ 
The concept of a stiffer barge is introduced to improve our understanding of the dynamic behaviour of the actual (very flexible) barge. For the 2D hydroelasticity analysis, the actual barge is stiffened gradually, up to the stiffer barge having 16 times larger stiffness compared to the actual barge. For the co-simulation only VBM predictions for the stiffer barge are carried out. The results of these investigations are shown in Figure $11 \& 12$.

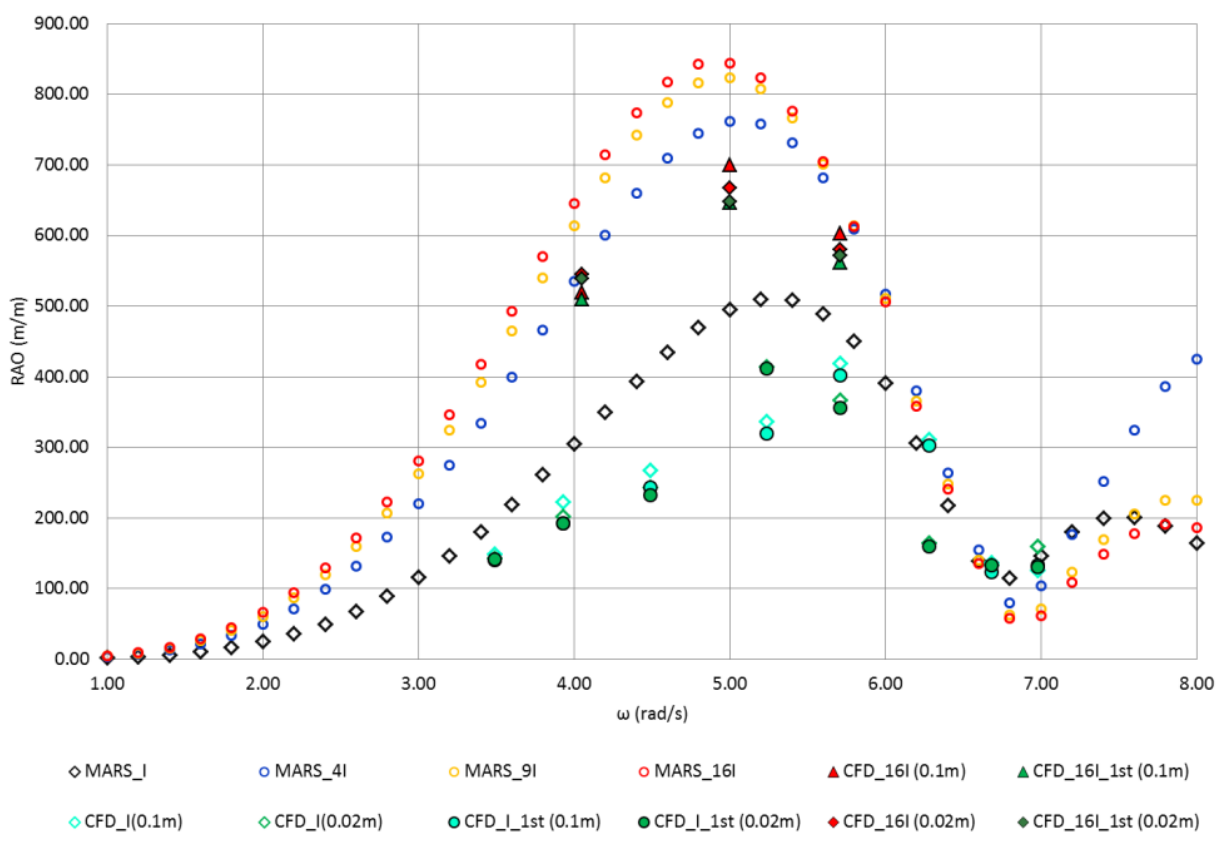

Figure 11: RAOs of VBM of the barge with different stiffness at $\mathrm{x} / \mathrm{L}=0.5$

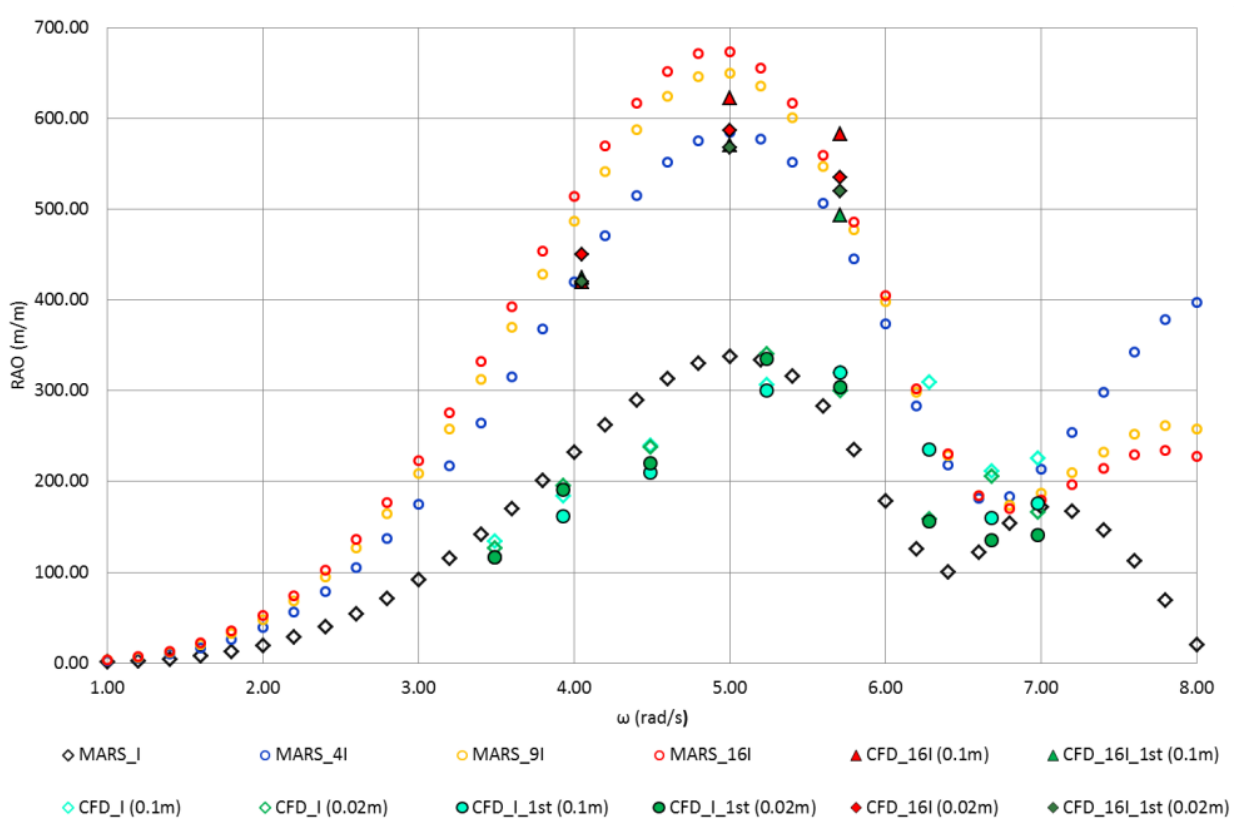

Figure 12: RAOs of VBM of the barge with different stiffness at x/L 0.66. 
The actual barge is denoted as the ' $\mathrm{I}$ ' and the barge that has 4, 9 and 16 times larger stiffness is denoted as '4I', '9I' and '16I', respectively. The response of the first harmonic of wave frequency is differentiated from the total average VBM using the suffix ' 1 st'

For the small wave amplitude, denoted as $(0.02 \mathrm{~m})$, as expected the difference between the total VBM and its $1^{\text {st }}$ harmonic are negligible for either the actual or stiffer barge. For the larger wave amplitude the differences between total and $1^{\text {st }}$ harmonic VBM are, by and large, relatively small for the actual barge. An exception to this observation is the VBM at $0.66 \mathrm{~L}$ from stern for frequencies above $6 \mathrm{rad} / \mathrm{s}$ where differences between total and $1^{\text {st }}$ harmonic VBM of the order of $25 \%$ are observed.

Larger differences between total and $1^{\text {st }}$ harmonic are observed for the stiffer barge and there is closer agreement between the first harmonics and the $2 \mathrm{D}$ hydroelasticity predictions, as illustrated in the Table 9.

Table 9: Ratio of VBM between MARS and CFD for actual and stiffer (16I) barge at Pt.7

\begin{tabular}{ccc}
\hline Ratio & Actual barge & 16I stiffer barge \\
\hline MARS/CFD_0.02m & 1.24 & 1.27 \\
MARS/CFD_0.1m & 1.51 & 1.21 \\
MARS/CFD_0.1m_1 ${ }^{\text {st }}$ harmonic & 1.59 & 1.3 \\
\hline
\end{tabular}

Bearing in mind that the so called stiffer barge is closer to conventional merchant ships in terms of its lowest natural frequency, a number of observations can be made on the apparent differences between the predictions using co-simulation and 2D linear hydroelasticity analysis for the actual barge.

The large flexibility of the actual barge appears to reduce the influence of higher harmonics in the VBM, though not as much post the first peak. These can only be attributed to the flow around the 3D flexible barge, which cannot be accurately simulated by the linear 2D hydroelasticity analysis for any wave amplitude, and particularly for the larger wave amplitude (see Figs $9 \& 10$ ). This, for lack of a better word, is described as nonlinearity due to flexibility for a free surface ship, which also include effects due to dependence of added mass and damping on motion amplitude. 
When comparing the stiffer barge the $1^{\text {st }}$ harmonic VBM are closer to the $2 \mathrm{D}$ linear hydroelasticity predictions, with differences of the order of $10-15 \%$ around resonance. What is observed in the VBM of the stiffer barge confirms to the expected nonlinear influences for typical merchant ships, i.e. free surface nonlinearities giving rise to higher harmonics.

At the moment it is not possible to further explain the $10-15 \%$ differences observed for the dynamically more conventional ship-like stiffer barge. However, differences of such magnitude are well within expectations of uncertainties relating to the different numerical processes associated with each numerical model and method.

\section{Concluding remarks}

The time domain hydroelastic investigation is carried out using commercially available software Star-CCM+ and Abaqus. The field equations are coupled using an iterative implicit scheme between STARCCM+ and Abaqus. The numerical solution for the stationary barge is compared to experimental measurements (for displacements only) and 2-D linear hydroelastic predictions. Calculations are carried out for both rigid body and flexible structural idealisations. Good agreement is achieved between time domain predictions and experimental measurements for displacement RAOs, with some exceptions especially at the forward section of the barge. Limited mesh density related convergence analysis indicates that the initial mesh choice based on wide-ranging experience with CFD modelling, denoted as coarse, is suitable for engineering and design predictions.

Although the comparisons for rigid body motions between the two numerical methods agreed well overall, large differences were observed in the bow and stern regions of the barge at lower frequencies. This is found to be due to strong bow and stern waves systems mainly influenced by the pitch, which are captured by STARCCM+. CFD solves nonlinear Navier-Stokes equations which makes it more realistic than the linear potential flow code. Nevertheless, it should be noted that the rigid body approximation is not suitable for this very flexible barge.

Comparisons made between the present coupling (or cosimulation) technique and the experimental measurements showed very few discrepancies. Very good agreement was observed at relatively low frequencies, but some differences were noted at higher frequencies. Of the two numerical methods, namely linear 2-D hydroelasticity and 
cosimulation, predictions using the coupled CFD method showed a better agreement with experiments as it allows for nonlinearities. The results show that the coupling technique investigated is reliable and compares well with experimental measurements.

Influence of flexibility is evident in the relatively low frequencies as the body deforms with the wave resulting in weak stern and bow waves; hence, lower vertical displacements when compared to the rigid body approach. The vertical bending moments calculated using the two numerical methods showed differences with increase in wave frequency. The agreement between the results improve when simulations were carried out using a smaller wave height demonstrating the fact that nonlinearities are one the major reasons for the differences between the numerical predictions. The 2-D linear hydroelastic theory is a powerful and faster tool to estimate the linear wave loads, and hence, a better choice than the coupling technique for the initial design stage of the vessel. However, when the wave conditions induce strong nonlinear behaviour a fully nonlinear approach such as the cosimulation could provide more accurate predictions.

\section{Acknowledgements}

The authors acknowledge the support of the Lloyd's Register Foundation through its University of Southampton Technology Centre and Lloyd's Register . The authors also acknowledge Professor Bernard Molin and Mr. Fabien Remy for their kindness in providing experimental data.

\section{References}

Andersen, I.M. V \& Jensen, J.J., 2014. Measurements in container ship of wave-induced hull girder stresses in excess of design values. Mar.Structs, 37, pp.54-85.

ASME, 2008. Procedure for Estimation and Reporting of Uncertainity due to Discretization in CFD Applications. Journal of Fluids Engineering, 130(7).

Benra, F.K., Dohmen, H.J., Pei, J., Schister, S. \& Wan, B., 2011. A comparison of one-way and two-way coupling methods for numerical analysis of fluid-structure interactions. Journal of Applied Mathematics, p.16 pages.

Bishop, R.E.D. \& Price, W.G., 1979. Hydroelasticiy of Ships, Cambridge University Press.

Bishop, R.E.D., Price, W.G. \& Tam, P.K.Y., 1977. A unified dynamic analysis of ship response to waves. Trans. R. Inst Nav. Architects, 119, pp.363-390.

Bishop, R.E.D., Price, W.G. \& Wu.Y, 1986. A general linear hydroelasticity theory of floating structures moving in a seaway. Phil. Trans. R. Soc. Lond, A316, pp.375-426.

Bloxom, A.L., 2014. Numerical simulation of the fluid-structure interaction of a surafce effect ship bow seal. Virginia Polytechnic Institue and State University.

Camilleri, J., Temarel, P. \& Taunton, D., 2015. Two-dimensional numerical modelling of slamming impact loads on high-speed craft. In 7th International Conference on HYEL. Split, Croatia, pp. 43-54. 
Carrica, P.M., Wilson, R. V \& Stern, F., 2006. Unsteady RANS simulation of the ship forward speed diffraction problem. Computers \& Fluids, 35(6), pp.545-570.

Causin, P., Gerbeau, J.. \& Nobile, F., 2005. Added-mass effect in the design of partitioned algorithms for fluid-structure problems. Computer methods in applied mechanics and engioneering, 194, pp.45064527.

Chen, X.J., Wu, Y.S., Cui, W.C. \& Jensen, J.J., 2006. Review of hydroelasticity theories of global response of marine structures. Ocean Engng, 33, pp.439-457.

Clough, R.W. \& Penzien, J., 1993. Dynamics of Structures, Berkely, CA: McGraw-Hill.

Connel, K.O. \& Cashman, A., 2016. Development of a numerical wave tank with reduced discretization error. In International Conference on Electrical, Electronics and Optimization Techniques. Chennai, India, pp. 3008-3012.

Dassault Systèmes, 2013. Abaqus 6.13-1 Manual, Providence, RI, USA.

Dhavalikar, S., Awasare, S., Joga, R. \& Kar, A.R., 2015. Whipping response analysis by one way fluid structure interaction-A case study. Ocean Engineering, 103, pp.10-20.

Ferrer, E. \& Montlaur, A., 2015. CFD for Wind and Tidal Offshore Turbines, Springer International Publishing.

Ferziger, J.. \& Peric, M., 2003. Computational Methods for Fluid Dynamics 3rd Editio., Springer, Berlin.

Fonseca, N. \& Guedes Soares, C., 2004. Experimental Investigation of the Nonlinear Effects on the Vertical Motions and Loads of a Containership in Regular Waves. J. Ship Res., 48(2), pp.118-147.

Hirdaris, S.E. \& Temarel, P., 2009. Hydroelasticity of ships: Recent advances and future trends. In Proceedings of the Institution of Mechanical Engineers, Part M: J. Engng Maritime Environment, 223, pp.305-330.

Hirdaris, S.E., White, N.J., Angoshtari, N., Johson, M.C., Lee, Y. \& Bakkers, N., 2010. Wave loads and flexible fluid-strutcure interactions: current developments and future directions. Ships and Offshore Structures, 5(4), pp.307-325. Available at: http://dx.doi.org/10.1080/17445301003626263.

Hirt, C.W. \& Nichols, B.D., 1981. Volume of Fluid (VOF) method for the dynamics of free boundaries. Journal of Computational Physics, 39, pp.201-225.

Hong, S., Kyoung, J., Kim, Y., Kim, S. \& Malencia, S., 2008. Validation of wave loads of a containership in oblique waves. In 6th Osaka Colloquim on Seakeeping and Stability of ships. pp. 10-117.

ITTC., 2011. The Seakeeping Committe final report and recommendations. In the Proceedings of 26th ITTC, Rio de Janerio, Brazil. , pp.183-245.

Kim, K.H., Bang, J.H., Kim, Y. \& Kim, S.J., 2013. Fully coupled BEM-FEM analysis of ship hydroelasticity in waves. In Marine Structures. pp. 71-99.

Kim, Y. \& Kim, K.H., 2009. Analysis of Hydroelasticity of Floating Shiplike Structure in Time Domain Using a Fully Coupled Hybrid BEM-FEM. J. Ship Res., 50(1), pp.31-47.

Lakshmynarayanana, P., Temarel, P. \& Chen, Z., 2015. Coupled Fluid-Structure Interaction to model Three-Dimensional Dynamic Behaviour of Ship in Waves. In 7th International Conference on HYEL. pp. 623-637.

Malenica, S., Moan, B., Remy, F. \& Senjanovic, I., 2003. Hydrelastic reponse of a barge to impulsive and non-impulsive wave loads. In Hydroelasticity in Marine Technology. pp. 107-115.

El Moctar, O., Schellin, T.E. \& Priebe, T., 2006. CFD and FE methods to predict wave loads and ship structure response. In 26th Symposium of Navalhydrodynamics. Rome, Italy.

Muzaferija, S., Peric, M., Sames, P. \& Schellin, T., 1998. A Two-Fluid Navier-Stokes Solver to Simulate Water Entry. In In Proceedings of the 22nd symposium on naval hydrodynamics. Washinton, DC, pp. 277-289. 
Oberhagemann, J., Kromer, M., Cabos, C. \& El Moctar, O., 2012. A fluid-structure coupling method based on field methods and a structural mode decomposition. In Hydroelasticity in Marine Technology. pp. $267-276$.

Oberhagemann, J., El Moctar, O. \& Schellin, T.E., 2008. Fluid-Structure Coupling to Assess Whipping Effects on Global Loads of a Large Containership. In 27th Symposium on Naval Hydrodynamics. Seoul, Korea.

Paik, K.J., Carrica, P.M., Lee, D. \& Maki, 2009. Strongly coupled fluid-structure interaction method for structural loads on surface ships. Ocean Engng, 36, pp.1346-1357.

Park, J.H. \& Temarel, P., 2007. The Influence of Nonlinearities on Wave-induced Motions and Loads Predicted by Two-dimensional Hydroelasticity Analysis. In Proceeding of the 10th International Symposium on Practical Design of Ships and Other Floating Structures,Houston, Texas, 1, pp.27-34.

Patankar, S. V \& Spalding, D.B., 1972. A calculation procedure for hear, mass and momentum transfer in three-dimensional parabolic flows. Int. Journal of Heat and Mass Transfer, 15(10), pp.1787-1806.

Peric, M., 2012. Wave impact, body motion and overset grids in Star-CCM+. In South East Asian Conference. Available at: http://www.cdadapco.com/sites/default/files/Presentation/WavesBodyOverset_MP.pdf.

Peric, M., Zorn, T., El Moctar, O., Schellin, T. \& Kim, Y.S., 2007. Simulation of Sloshing in LNG-Tanks. In OAME.

Remy, F., Moilin, B. \& Ledoux, A., 2006. Experimental and numerical study of wave response of a flexible barge. In 4th International Conference on Hydroelasticity in Marine Technology. pp. 255-264.

Richter, T. \& Wick, T., 2013. On time discretizations of Fluid-structure interactions, Spinger.

Roache, P.J., 1998. Verification and Validation in Computational Science and Engineering, Albuquerque, New Mexico: Hermosa Publishers.

Rugonyi, S. \& Bathe, K.J., 2001. On finite element analysis of fluid flows coupled with structural interaction. CMES-Comp. Modeling Eng. Sci., 2(2), pp.195-212.

Seng, S., Andersen, I.M. V \& Jensen, J.J., 2012. On the influence of hull girder flexibility on the wave induce bending moments. In 6th International Conference on Hydroelasticity in Marine Technology.

STAR-CCM+, 2012. STAR-CCM+ version 8.04 manual.

Storhaug, G., Choi, B.K., Moan, T. \& Hermundstad, O.A., 2010. Consequence of whipping and springing on fatigue for a 8600TEU container vessel in different trades based on model tests. In 11th International Symposium on a practical design of ships and other floating structures. pp. 1180-1189.

Taghipour, R., Perez, T. \& Moan, T., 2008. Time-Domain Hydroelatic Analysis of a Flexible Marine Structure using State-Space Models. J. Offshore Mech. Arct. Eng, 131(1).

Takami, T., Matsui, S., Oka, M. \& Iijima, K., 2018. A numerical simulation method for predicting global and local hydroelastic response of a ship based on CFD and FEA coupling. Marine Structures, 59, pp.368386.

Tallec, P. Le \& Mouro, J., 2001. Fluid structure interaction with large dispalcements. Comput. Meth. Appl. Mech. Engrg, 190, pp.3039-3067.

Tang, H.S., Jobes, S.C. \& Sotiropoulos, F., 2003. An overset-grid method for 3D unsteady incompressible flows. Journal of Computational Physics, 191, pp.567-600.

Wang, Z.J., 1995. A fully conservative interface algorithm for overlapping grids. Journal of Computational Physics, 122, pp.96-106.

Watanabe, I., Keno, M. \& Sawada, H., 1989. Effects of bow flare shape on wave loads of a container ship. Journal of the Society of Naval Architects of Japan, 166, pp.259-299.

Weymouth, G., Wilson, R. \& Stern, F., 2005. RANS Computational Fluid Dynamics Predictions of Pitch and Heave Ship Motions in Head Seas. Journal of Ship Research, 49(2), pp.80-97. 
Wilson, R., Paterson, E. \& Stern, F., 1998. Unsteady RANS CFD method for naval combatants in waves. In Proc, 22th Symp. on Naval Hydrodynamics. pp. 532-549.

Wilson, R. V, Stern, F., Coleman, H.W. \& Paterson, E.G., 2001. Comprehensive Approach to Verification and Validation of CFD Simulations- Part 2: Application of Rans Simulation of a Cargo/Container Ship. Journal of Fluids Engineering, 123, pp.803-810.

Wu, M. \& Hermundstad, O.A., 2002. Time-domain simulation of wave-induced nonlinear motions and loads and its applications in ship design. Marine Structures, 15(6), pp.561-597.

Wu, Y., Chen, R. \& Lin, J., 2003. Experimental Technique of Hydroelastic Ship Model. In Hydroelasticity in Marine Technology. pp. 131-142.

Wu, Y.S. \& Cui, W.C., 2009. Advances in the three dimensional hydroelasticity of ships. In Proceedings of the Institution of Mechanical Engineers, Part M: J. Engng Maritime Environment, 223, pp.331-348. 